\title{
A review on human reinstatement studies: an overview and methodological challenges
}

\author{
Jan Haaker, ${ }^{1,2}$ Armita Golkar, ${ }^{2}$ Dirk Hermans, ${ }^{3}$ and Tina B. Lonsdorf ${ }^{1}$ \\ ${ }^{1}$ Institute for Systems Neuroscience, University Hospital Hamburg-Eppendorf, 20246 Hamburg, Germany; ${ }^{2}$ Karolinska Institute, \\ Department of Clinical Neuroscience, 17177 Stockholm, Sweden; ${ }^{3}$ Faculty of Psychology and Educational Sciences, University \\ of Leuven, 3000 Leuven, Belgium
}

\begin{abstract}
In human research, studies of return of fear (ROF) phenomena, and reinstatement in particular, began only a decade ago and recently are more widely used, e.g., as outcome measures for fear/extinction memory manipulations (e.g., reconsolidation). As reinstatement research in humans is still in its infancy, providing an overview of its stability and boundary conditions and summarizing methodological challenges is timely to foster fruitful future research. As a translational endeavor, clarifying the circumstances under which (experimental) reinstatement occurs may offer a first step toward understanding relapse as a clinical phenomenon and pave the way for the development of new pharmacological or behavioral ways to prevent ROF. The current state of research does not yet allow pinpointing these circumstances in detail and we hope this review will aid the research field to advance in this direction. As an introduction, we begin with a synopsis of rodent work on reinstatement and theories that have been proposed to explain the findings. The review however mainly focuses on reinstatement in humans. We first describe details and variations of the experimental setup in reinstatement studies in humans and give a general overview of results. We continue with a compilation of possible experimental boundary conditions and end with the role of individual differences and behavioral and/or pharmacological manipulations. Furthermore, we compile important methodological and design details on the published studies in humans and end with open research questions and some important methodological and design recommendations as a guide for future research.
\end{abstract}

Learning to predict danger from the environment ("fear conditioning" in experimental terms) as well as learning when these environmental contingencies change is critical for adaptive behavior. The latter, referred to as "extinction," does not, in most circumstances, erase conditioned fear memories (conditioned stimulus [CS]-unconditioned stimulus [US] association), but generates competing, fear-inhibitory extinction memories (CS - no US) both of which coexist after successful extinction (Bouton 2004; Myers and Davis 2007). Insufficient expression of extinction memories upon reconfrontation with a conditioned stimulus (CS) results in return of fear (ROF), which represents a likely basis of relapse that occurs after successful extinction-based cognitive behavioral therapy (CBT) (for an overview, see, e.g., Vervliet et al. 2013b). ROF can be experimentally induced in the laboratory following successful extinction through the mere passage of time ("spontaneous recovery"), induction of contextual change ("renewal"), or by exposure to unsignaled USs ("reinstatement") (for an overview in animals, see Bouton 2004; in humans, see Vervliet et al. 2013b).

Reinstatement was first described in animals by Pavlov (Pavlov 1927), studied further by Rescorla (Rescorla and Heth 1975; Rescorla and Cunningham 1977), and was systematically investigated in rodents by Bouton and colleagues (e.g., Bouton and Bolles 1979; Bouton and King 1983; Bouton 1984). In human research, studies of ROF phenomena, and reinstatement in particular, began only a decade ago and have recently begun to be more widely used, e.g., as outcome measures for fear/extinction memory manipulations. As reinstatement research in humans is still in its infancy, providing an overview of the reliability and possible boundary conditions of this phenomenon and summarizing methodological challenges is timely to foster fruitful future hu-

\section{Corresponding author: t.lonsdorf@uke.de}

Article is online at http://www.learnmem.org/cgi/doi/10.1101//m.036053.114. man research. As a translational endeavor, clarifying the circumstances under which (experimental) reinstatement occurs may offer a first step toward understanding relapse as a clinical phenomenon and pave the way for the development of new pharmacological or behavioral ways to prevent ROF.

Currently, however, our knowledge of experimental boundary conditions as well as biological or trait factors for reinstatement is very limited in humans and methodological work is critically needed. Therefore, we focus herein on the reports of reinstatement in humans unconfounded by other experimental manipulations (e.g., reconsolidation, drugs, etc.). The systematic overview of human work provided in this review represents a first step along this avenue and will hopefully aid the research field to advance and grow. For introductory purposes and to allow the reader to put the human work into a bigger context, we also provide an overview of mechanisms and theories derived from rodent work that have been put forward to explain the reinstatement phenomenon.

We begin the review of human reinstatement literature with a general summary of details and variations of the experimental setup in reinstatement studies in humans and review reinstatement effects in the literature. We continue with a comprehensive compilation of possible experimental boundary conditions and methodological details in human work and end with the role of individual differences and behavioral and/or pharmacological manipulations in humans. Additionally, we provide a tabular compilation of important methodological and design details on

\footnotetext{
C 2014 Haaker et al. This article is distributed exclusively by Cold Spring Harbor Laboratory Press for the first 12 months after the full-issue publication date (see http://learnmem.cshlp.org/site/misc/terms.xhtml). After 12 months, it is available under a Creative Commons License (AttributionNonCommercial 4.0 International), as described at http://creativecommons. org/licenses/by-nc/4.0/.
} 
the published studies in humans throughout the manuscript. In closing, we discuss open research questions and derive methodological and design recommendations as a guide for future human studies. The latter is of paramount importance as a comprehensive characterization, clean study design, as well as uniform statistical tests to evaluate reinstatement effects in humans are needed to advance a more comprehensive understanding of this important phenomenon.

\section{A synopsis of rodent work on reinstatement and the mechanistic implications}

Reinstatement was first described nearly a century ago (Pavlov 1927), but only decades later Rescorla and colleagues (Rescorla and Heth 1975; Rescorla and Cunningham 1977) used the reinstatement phenomenon to demonstrate that extinction does not result in erasure of the originally learned association.

Rescorla demonstrated that reexposure to the US after extinction reinstates fear even when the US was predicted by a CS as well as when reinstatement US presentations and test were separated in time (Rescorla and Heth 1975). These phenomena were interpreted as a restrengthening of the US representation (Rescorla and Heth 1975; Rescorla and Cunningham 1977). The theory (Rescorla 1979) grounded on these results was later introduced as that a release from inhibition may underlie the reinstatement phenomenon. During extinction the "CS+-US association" is thought to be inhibited by formation of an "extinction context-no US" memory that "masks" the original learning (Rescorla 1979). Reexposure of the US during reinstatement (in the inhibitory extinction context) unmasks or restores the excitatory CS-US association consequently leading to reinstatement at test in the same context. In other words, the extinction context acquires the ability to enhance the threshold at which the CS-US association is activated during extinction and US-alone reexposure during reinstatement reduces this threshold, which subsequently leads to ROF to previously extinguished CSs (Rescorla and Cunningham 1977; Rescorla 1979). The above prediction however is only valid when extinction, reinstatement, and test context are identical, as commonly done in these early studies. Thus, this theory has later been abandoned, when it was shown that it is sufficient to observe that reinstatement and test context were identical (Bouton and Bolles 1979; Bouton and King 1983; Bouton and Peck 1989).

The role of the reinstatement context and its excitatory properties was established by Bouton and colleagues in a series of experiments (e.g., Bouton and Bolles 1979; Bouton and King 1983; Bouton 1984; Frohardt et al. 2000). The amount of reinstatement was, for example, correlated with the amount of context conditioning the animals displayed at the start of the test session (Bouton and King 1983 [Exp. 2]; Bouton 1984). Also, rodents that were extinguished to the reinstatement context after reinstatement but before CS presentations at test did not show reinstatement to the CS in this context (Bouton and Bolles 1979; replicated in Westbrook et al. 2002). In addition, no reinstatement was observed when reinstatement took place in a novel or the original conditioning context and the similarity to the extinction context seemed irrelevant in this scenario (Bouton and King 1983 [Exp. 2]).

In sum, the work by Bouton and colleagues suggests that reinstatement to a CS depends on conditioning to the reinstatement context. Two hypotheses have been put forward to explain these findings. First, the summation hypothesis, which bends to the Rescorla-Wagner model and views the context as a stimulus whose excitatory or inhibitory association with the US sums up with that of the CS and the US (Rescorla and Wagner
1972; Bouton and Bolles 1979; Bouton and King 1983 [Exp. 2]). This hypothesis suggested that the remaining excitatory value of the CSs after extinction is summed with the excitatory value of the newly conditioned context (the reinstatement context). Contrary to predictions however, results were specific for extinguished stimuli, as only these were affected by context conditioning through reinstatement, while responses to unextinguished CSs were not further enhanced (Bouton and King 1986). In addition, results for partially reinforced stimuli (Bouton 1984; Bouton and King 1986) were a challenge to this hypothesis and, as a result of these limitations, Bouton rejected this hypothesis in favor of the retrieval model. According to this model, the context functions as an "occasion setter." Contextual fear generated by reinstatement USs gates retrieval of the latent "CS-US association" (acquisition memory, context independent) over the competing "CS-no US" association (extinction memory, context dependent) resulting in ROF (Bouton et al. 1993; Bouton 2004). According to this approach, extinction and acquisition memory coexist after extinction and conditioned responding at test is determined by the dominance of one over the other. Observations of more pronounced ROF when test and reinstatement context are identical is in line with this theory as well as the absence of ROF when the reinstatement context was extinguished following reinstatement US presentation (Bouton and Bolles 1979; replicated in Westbrook et al. 2002). The retrieval model is able to explain most of the circumstances when ROF is observed in rodents and still represents the prevailing explanation. Some findings however challenge this theory. For example, reinstatement occurs when reinstatement and test context are different, provided that the reinstatement and the extinction context are identical (Westbrook et al. 2002 [Exp. 2b]). Reinstatement in this experimental design was enhanced beyond renewal effects (Westbrook et al. 2002 [Exp. 3]) and was strongest for a CS for which the corresponding extinction context served as the reinstatement context (Westbrook et al. 2002 [Exp. 4]).

Westbrook and colleagues revisited the hypothesis of mediated conditioning (Holland 1981), in an attempt to explain their findings. They propose an additional function of context conditioning in reinstatement, beyond associations with the US: during extinction, the CS becomes associated with the corresponding context and after reinstatement the US also becomes associated with this context. Through this common association of the "CS and the context" and the "context and the US," reinstatement is mediated through new contextual learning. A similar explanation represents the associative chaining framework (Hall 1996). Through the common association outlined above (CScontext and context-US), the extinguished link between the CS and the US can be renewed during test via CS presentation which activates the representation of the context and thereby also of the US. The theories of mediated conditioning and associative chaining differ from each other only with respect to when the context links the extinguished CS to the US. Nevertheless, the hypothesis of mediated conditioning cannot explain ROF that is observed when US reexposure took place in a novel context that was never associated with the CS (no common association between the CS-context-US) and then tested in a different, novel context (Westbrook et al. 2002 [Exp. 3, group BC]). However, based on the retrieval model, response enhancement in this experimental design may be explained by a generalization of fear from the conditioned reinstatement-context to the test context that goes beyond renewal (as discussed in Westbrook et al. 2002).

One attempt to model these results derived from rodent studies as well as one human study (LaBar and Phelps 2005) resulted in the attentional-associative model (Schmajuk et al. 2007). According to this model, the CS and the context compete for attention with the US. Due to the discrete presentations of the CS, 
a strong CS-US association, but only a weak context-US association is formed during acquisition. During extinction, the context-US associations acquire inhibitory properties and the CSUS association remains intact. In addition, attention to the context and the CS decreases during extinction, until the presentation of the US during reinstatement increases attention to the context (due to the lack of a present CS). This enables the formation of an excitatory context-US association, as well as an attentional shift to the CS during test. When reinstatement and test occur in the same context, reinstatement was proposed to result from decreased contextual inhibition and increased attention to the CS, leading to a reactivation of the CS-US association. When reinstatement occurred in the extinction context and the CS was tested in a context different from that, reinstatement resulted from enhanced attention to the CS and reactivated CScontext and context-US associations.

Interestingly, Pearce and Hall (1980) already proposed that processes of attention are necessary to enable associative learning and that attention is a function of experience (for review, see Pearce and Bouton 2001; Pearce and Hall 1980). According to the model, learning declines if the event following the CS is completely predicted by the CS. This model accounts for the assumptions in the former model of low attention to the CS and the context at the end of extinction, as well as the enhanced association of the context with the unexpected presentation of the US during reinstatement.

The theoretical frameworks for reinstatement outlined above are not mutually exclusive as multiple mechanisms that underlie reinstatement processes might act in compound or in isolation, depending on the specific experimental design and demand (e.g., similarity of extinction, reinstatement, and test context). If extinction occurs in one context, which is different from the context of reinstatement and test (which in turn are identical), reinstatement can be explained by a retrieval of the CS-US association elicited by the conditioned context (Bouton and Bolles 1979; Bouton 2004). Additional processes, e.g., shifts in attention and common associations, may add to the phenomenon and underlie response enhancement in other reinstatement designs (e.g., when extinction and reinstatement context are identical but both different from the test context [Westbrook et al. 2002]).

As it is beyond the scope of this manuscript to give a comprehensive picture of the past 40 years of rodent work on the reinstatement phenomenon and the different theoretical explanations, we refer the interested reader to other excellent and important sources (Rescorla 1979; Westbrook et al. 2002; Bouton 2004).

While these systematic investigations reveal the important role of the context in reinstatement in rodents, the importance of contextual influences in humans has been shown as well, albeit mechanistic explanations and comprehensive studies are missing.

\section{Reinstatement in humans}

\section{Type of conditioning protocol and generalized vs. differential reinstatement effects}

In humans, reinstatement effects have been observed in singlecue studies (LaBar and Phelps 2005 [Exp. 1]; Schiller et al. 2008) mirroring experimental protocols and results of rodent work (Frohardt et al. 2000; Harris et al. 2000; Westbrook et al. 2002; Morris et al. 2005; Laurent and Westbrook 2010). The majority of human studies, however, used differential protocols. In differential conditioning, typically one of two initially neutral stimuli is paired with the US during acquisition, while the other one (CS - ) is not. Differential protocols allow for within-subject comparisons of the US-associative memory and can thus control for the effects of orienting responses and sensitization effects (as these processes would affect CS + and CS - in a similar vein) and allow for testing of generalization effects. In contrast, only one rodent study used a differential conditioned suppression protocol in mice demonstrating differential (that is, CS+-specific) ROF in the reinstatement but not in the no-reinstatement US control group (Dirikx et al. 2007a).

In humans the picture is complex: Differential protocols yielded evidence for reinstatement specifically to the $\mathrm{CS}+$, but not to the CS - (differential reinstatement). While some of the studies also observed, to a certain degree, enhanced responding to the CS - despite a more pronounced enhancement for the CS+ (Milad et al. 2005; Dirikx et al. 2007b; Kull et al. 2012), other studies demonstrate ROF to both CS + and CS - to the same degree (generalized reinstatement). Whether ROF is specific for the CS + or generalized to the CS-(s) is important, since the ability to discriminate safety cues from threat cues is negatively associated with pathological anxiety (Lissek et al. 2005) and predictive of resilient responding to life stress (Craske et al. 2012) (also see the section "Self-reported anxiety" below). Furthermore, it's not the mere enhancement of responses (observed in both differential and generalized reinstatement), but the ability to maintain a discrimination under aversive circumstances which might critically underlie long-term remission and/or resilience.

Interestingly, the observation of nondifferential (generalized) ROF is also evident in other ROF phenomena such as renewal (for review, see Vervliet et al. 2013a) and spontaneous recovery (Norrholm et al. 2008). Further complicating matters, often a mixture of differential, generalized, and no reinstatement effects in different dependent measures is reported within one study (see Table 1 for a detailed summary of the results of human studies). The high frequency of nondifferentially enhanced responding following reinstatement may question whether genuine association-based processes (e.g., stimulus generalization due to stimulus similarity) or rather sensitization or orienting effects to uncertainty are underlying mechanisms and these need to be controlled for using an adequate study design (see recommendations for future studies below [Table 4]). As discussed in the framework of renewal studies (Vervliet et al. 2013a), generalized ROF, however, does not preclude genuine association-based effects to the CS+ but may result from associative learning to the CS- as well. Inclusion of additional control stimuli that are present only during the acquisition of fear and the reinstatement test (i.e., not extinguished stimulus) or only during reinstatement test (e.g., novel stimulus) may be used to control enhancement of responses due to association between the stimulus and the context and thus prove useful in future studies.

Inclusion of a control group that did not receive any reinstatement USs also allows controlling for effects that are due to the experimental break between extinction and reinstatement test (e.g., sensitization or orienting responses and/or return of fear phenomena as renewal or spontaneous recovery) (see recommendations for future studies below [Table 4]) and the importance of control groups becomes evident from the fact that in some human studies, enhanced reactions are not only observed in the experimental but also in the no-reinstatement control group (see Table 1; Fig. 1; Hermans et al. 2005; Dirikx et al. 2007b, 2009; Kull et al. 2012; two unpublished data sets [Dirikx 2006]).

\section{Dependent measurements}

In human studies, CRs are commonly indexed by skin conductance responses (SCRs) or levels (SCL), fear potentiated startle (FPS), fear and US expectancy ratings (ratings), or reaction time tasks (RT) (see later, Table 3). Only recently, studies using fMRI have emerged (Kattoor et al. 2013a,b; Lonsdorf et al. 2014a,b). It is obvious from an overview of the results in these different 
Table 1. Reinstatement effects in different dependent measures in the included studies

\begin{tabular}{|c|c|c|c|c|}
\hline \multirow[b]{2}{*}{ Reference } & \multirow[b]{2}{*}{$\begin{array}{l}\text { Differential response } \\
\text { enhancement (DR) }\end{array}$} & \multicolumn{2}{|c|}{ Reinstatement group } & \multirow{2}{*}{$\begin{array}{c}\text { Control group } \\
\text { (if applicable) }\end{array}$} \\
\hline & & $\begin{array}{l}\text { Generalized response } \\
\text { enhancement (GR) }\end{array}$ & $\begin{array}{l}\text { No-response } \\
\text { enhancement }\end{array}$ & \\
\hline Dirikx et al. (2004) & - $\mathrm{RT}^{\mathrm{b}}$ & $\begin{array}{l}\text { - Fear ratings (even though } \\
\text { stronger for CS }+ \text { ) } \\
\text { - US expectancy }\end{array}$ & & - Fear ratings to $\mathrm{CS}+{ }^{\mathrm{a}}$ \\
\hline $\begin{array}{l}\text { Hermans et al. } \\
\text { (2005) }\end{array}$ & $\begin{array}{l}\text { - Fear ratings }{ }^{\mathrm{b}} \\
\text { - Reaction times } \\
\text { - US expectancy }\end{array}$ & & & - Reaction times (DR) \\
\hline \multicolumn{5}{|l|}{$\begin{array}{l}\text { LaBar and Phelps } \\
\text { (2005) }\end{array}$} \\
\hline $\begin{array}{l}\text { Exp. } 1(\mathrm{SC}) \\
\text { Exp. } 2\end{array}$ & $\begin{array}{l}\text { - SCRs (same context) } \\
\text { - SCRs }\end{array}$ & & - SCRs (different context) & \\
\hline Milad et al. (2005) & - $\mathrm{SCL}^{\mathrm{C}}$ & & & \\
\hline $\begin{array}{l}\text { Norrholm et al. } \\
\text { (2006) }\end{array}$ & $\begin{array}{l}\text { - FPS } \\
\text { - US expectancy }\end{array}$ & & & \\
\hline Dirikx (2007b) & - US expectancy & $\begin{array}{l}\text { - Fear ratings (but time } \times \mathrm{CS} \\
\text { type } \times \text { group interaction ns) } \\
\text { - Reaction times }\end{array}$ & & - US expectancy \\
\hline Schiller et al. (2008) & - SCRs (SC) & & & \\
\hline Dirikx et al. (2009) & & $\begin{array}{l}\text { - Fear ratings } \\
\text { - US expectancy } \\
\text { - RT (mainly driven by the CS-) }\end{array}$ & & $\begin{array}{l}\text { - US expectancy } \\
\text { (mainly to the CS-) }\end{array}$ \\
\hline Kull et al. (2012) & $\begin{array}{l}\text { - US expectancy (trend: } \\
P=0.07)\end{array}$ & $\begin{array}{l}\text { - US expectancy } \\
\text { - SCRs }\end{array}$ & & $\begin{array}{l}\text { - US expectancy (GR) } \\
\text { - SCRs (GR) }\end{array}$ \\
\hline $\begin{array}{l}\text { Golkar and Öhman } \\
\text { (2012) }\end{array}$ & $\begin{array}{l}\text { - FPS (unmasked, delayed } \\
\text { extinction group) } \\
\text { - FPS (masked, both delayed } \\
\text { and immediate extinction) } \\
\text { - US expectancy (unmasked, } \\
\text { both delayed and immediate } \\
\text { extinction) } \\
\text { - US expectancy (masked, } \\
\text { immediate extinction) }\end{array}$ & $\begin{array}{l}\text { - US expectancy (masked, } \\
\text { delayed extinction) }\end{array}$ & $\begin{array}{l}\text { - FPS (unmasked, } \\
\text { immediate extinction) }\end{array}$ & \\
\hline $\begin{array}{l}\text { Sokol and Lovibond } \\
\text { (2012) }\end{array}$ & & $\begin{array}{l}\text { - SCL (for both same and } \\
\text { different US } \text { reinstatement groups) } \text { - US expectancy (same-US } \\
\text { group) } \\
\text { - US expectancy (different US } \\
\text { group for new-US) }\end{array}$ & $\begin{array}{l}\text { - US expectancy (ratings } \\
\text { for the US } S_{\text {acquisition in }} \\
\text { the different } \\
\text { US } S_{\text {reinstatement }} \text { group) }\end{array}$ & \\
\hline Kattoor et al. (2013a) & $\begin{array}{l}\text { - Parahippocampal activation at } \\
0.001 \text { (uc) and } 0.09 \text { (SVC }\left(\mathrm{FWWE}_{\mathrm{FWE}}\right.\end{array}$ & & - US expectancy & \\
\hline $\begin{array}{l}\text { Kattoor et al. } \\
\quad(2013 b)\end{array}$ & $\begin{array}{l}\text { - Cerebellar activation (Crus I, } \\
\text { lobule IX, right Crus II, right } \\
\text { lobule I-IV and V) }\end{array}$ & & & \\
\hline $\begin{array}{l}\text { Kindt and Soeter } \\
\text { (2013) }\end{array}$ & - US expectancy & $\begin{array}{l}\text { - FPS } \\
\text { - SCRs }\end{array}$ & & \\
\hline $\begin{array}{l}\text { Gazendam and Kindt } \\
\text { (2012) }\end{array}$ & & $\begin{array}{l}\text { - FPS } \\
\text { - US expectancy }\end{array}$ & & \\
\hline $\begin{array}{l}\text { Sevenster et al. } \\
\quad(2012 b)\end{array}$ & $\begin{array}{l}\text { - US expectancy (noninstructed } \\
\text { extinction) } \\
\text { - FPS (in noninstructed and } \\
\text { instructed extinction groups, } \\
\text { though more pronounced on } \\
\text { a descriptive level in the } \\
\text { noninstructed extinction } \\
\text { group) }\end{array}$ & & $\begin{array}{l}\text { - SCR (in instructed and } \\
\text { noninstructed } \\
\text { extinction groups) } \\
\text { - US expectancy } \\
\text { (instructed extinction }^{\text {group) }}\end{array}$ & \\
\hline Golkar et al. (2013a) & - Fear ratings to contexts & $\begin{array}{l}\text { - Fear ratings to contexts } \\
\text { - FPS to cues } \\
\text { - SCRs to cues and contexts } \\
\text { - FPS (irrespective of number of } \\
\text { extinction trials) }\end{array}$ & $\begin{array}{l}\text { - Fear ratings to cues } \\
\text { - FPS to cues }\end{array}$ & \\
\hline $\begin{array}{l}\text { Golkar et al. (2013b) } \\
\text { Lonsdorf et al. } \\
\text { (2014b) }\end{array}$ & - SCRs & & & \\
\hline Discovery sample & & $\begin{array}{l}\text { - SCRs to contexts } \\
\text { - Ratings to cues } \\
\text { - dmPFC }\end{array}$ & $\begin{array}{l}\text { - SCRs to cues } \\
\text { - Ratings to contexts }\end{array}$ & \\
\hline
\end{tabular}


Table 1. Continued

\begin{tabular}{|c|c|c|c|c|}
\hline \multirow[b]{2}{*}{ Reference } & \multirow[b]{2}{*}{$\begin{array}{l}\text { Differential response } \\
\text { enhancement (DR) }\end{array}$} & \multicolumn{2}{|c|}{ Reinstatement group } & \multirow{2}{*}{$\begin{array}{c}\begin{array}{c}\text { Control group } \\
\text { (if applicable) }\end{array} \\
\begin{array}{c}\text { Significant response } \\
\text { enhancement }\end{array}\end{array}$} \\
\hline & & $\begin{array}{l}\text { Generalized response } \\
\text { enhancement (GR) }\end{array}$ & $\begin{array}{l}\text { No-response } \\
\text { enhancement }\end{array}$ & \\
\hline Replication sample & & $\begin{array}{l}\text { - Amygdala-SCR correlation } \\
\text { - Anterior hippocampus } \\
\text { - SCRs to cues and contexts } \\
\text { - Amygdala } \\
\text { - Anterior hippocampus }\end{array}$ & $\begin{array}{l}\text { - Ratings to cues and } \\
\text { contexts }\end{array}$ & \\
\hline
\end{tabular}

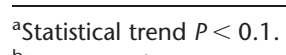

${ }^{b}$ Between reinstatement and control group only trendwise difference (in group $\times$ time $\times$ CS type ANOVA).

'Significant for $\mathrm{CS}+$, nonsignificant on descriptive level for $\mathrm{CS}-$, but no stats for discrimination reported.

"Only reported for "extinguishers" at least 50\% extinction.

eAlso when testing extinguishes (50\% criterion).

${ }^{\mathrm{f}} \mathrm{No}$ main effect of time is reported, but the graphs and the text suggest it.

${ }^{9}$ No statistics reported but the graph suggests it.

${ }^{h}$ No statistics reported and the graph suggests generalized reinstatement (only reported that it is not differential reinstatement).

(DR) Differential reinstatement, (GR) generalized reinstatement, (SC) single-cue experiment (thus no distinction between DR and GR possible).

measurement modalities (see Table 1; Fig. 1), that the type of dependent measurement does not explain the occurrence of differential vs. generalized reinstatement vs. nonsignificant reinstatement. This suggests that different dependent measures do not seem to be differently susceptible to the reinstatement effect as the proportion of differential vs. generalized effects is similar for all measures. From Figure 1, it seems as if reinstatement effects in the control group (no-reinstatement US group) is mainly observed in nonphysiological measures (ratings, RT), but it has to be noted that only few studies have employed control groups (see later for details [Table 3]) and only three of these (Norrholm et al. 2006; Kull et al. 2012; Sokol and Lovibond 2012) have recorded psychophysiological parameters (FPS, SCL, or SCR).

Individual studies have mainly relied on single psychophysiological measures and few studies have acquired multiple psychophysiological measures (Sevenster et al. 2012a; Haaker et al. 2013b; Kindt and Soeter 2013). As different psychophysiological measures are thought to tap different processes, comparability between the results of different studies is not straightforward. SCRs, for example, reflect contingency awareness while FPS is thought to be more fear-specific (e.g., Weike et al. 2007). To promote comparability between studies, future work should focus on multimodal assessments and report reinstatement effects in all measures acquired. In addition, calculation of reinstatement effects in measurements of baseline or contextual anxiety is needed to draw conclusions of the specificity underlying the ROF as well as to investigate sensitization effects, e.g., assessment of ITI startle or baseline startle measurement.

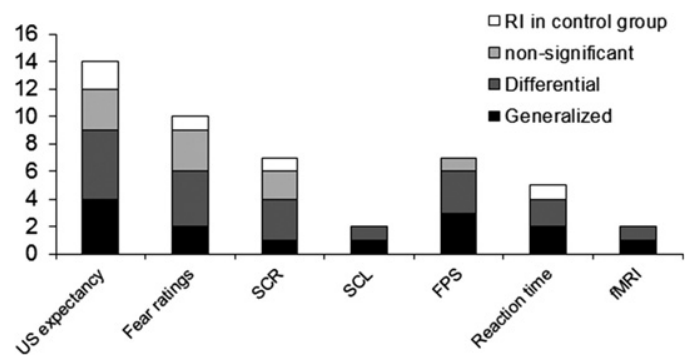

Figure 1. Number of studies reporting significant reinstatement (RI) in the control group, no significant, differential, or generalized RI, split up for different dependent measures.

\section{Calculation of reinstatement effects}

Due to the fact that the reinstatement effect in humans does not last over many nonreinforced test trials, the exact way of statistically quantifying it is important. Statistical calculations vary widely in between and within laboratories (see later, Table 3) and some recommendations would certainly aid the field in promoting comparability between studies and reducing arbitrary testing (see also recommendations for future studies below [Table 4]). While some authors have conducted single-trial analyses others have used blocks of two to six trials for statistics (see later, Table 3). As single-trial data, and in particular psychophysiological measures, tend to be rather noisy, they might be more prone to suffer from low reliability whereas small blocks of trials (e.g., two to three trials/CS type) may better capture the expected reinstatement induced response enhancement and yield more robust information. On the downside, trial blocks may include trials that reflect an already faded or extinguished phenomenon and thus might underestimate the effect. In any case, single-trial graphs should be presented to allow for an evaluation of the duration and differentiality of the effects.

Most studies have performed the crucial statistical test for reinstatement effects comparing CRs occurring immediately before to CRs immediately following reinstatement USs in a 2 (time) $\times$ 2 (CS type) ANOVA (see later, Table 3 "factor time in RI"). Some studies have performed statistical analyses separately for CS types $(\mathrm{CS}+/ \mathrm{CS}-)$ or the experimental and the no-reinstatement US control group (if included). While this provides important additional information, the critical test is a direct statistical comparison of responses to both CS types and time-points (prior to vs. postreinstatement) as well as between groups (if applicable). This is a significant difference between both time-points (main effect of time) and may indicate a generalized reinstatement of responses and CS-type specific changes (CS $\times$ time interaction) after reinstatement may imply a differential enhancement of responses. However, this interaction in an analysis comprising of both CS types and time-points denotes a differential reinstatement that cannot be inferred by separate testing of CS-types or time-points.

The factor time (prior to vs. post-reinstatement) requires an additional note. In single-day studies, reinstatement follows immediately upon an extinction or a second extinction (reextinction) phase allowing for a direct comparison between CSs elicited immediately before and after the reinstatement manipulation. Using a delayed reinstatement test occurring on a different day 
than acquisition and extinction also warrants caution. When no other test trials (see above) precede reinstatement US administration on the same day (as in, e.g., Schiller et al. 2008, 2010) an unequivocal attribution of response enhancement to reinstatement processes is not possible. In this scenario, initial reactivity, orienting responses, and spontaneous recovery effects likely also contribute to response enhancement.

Furthermore, the crucial test for reinstatement (time $\times$ CS type ANOVA) can be extended to a time $\times$ CS type $\times$ group (reinstatement vs. control group) ANOVA, which provides the most reliable information about genuine reinstatement effects. To date, only one-third of the human studies have used a no-reinstatement US control group and some of these even report significant response enhancement in the control group that did not receive unsignaled USs. This highlights the importance of the necessity to control for nonspecific effects and more work is needed to understand the processes underlying this nonspecific response enhancement in no-reinstatement US control groups.

In sum, genuine reinstatement effects have to be quantified by a repeated measures analysis involving time, CS-type, and possibly group (reinstatement vs. control group). A main effect of time (where post-reinstatement $>$ prior to reinstatement) can be interpreted as a generalized reinstatement effect, while a time $\times$ CS type interaction would be required for differential reinstatement. If both tests turn out to be significant, a generalized reinstatement that might be most pronounced for one CS type can be concluded. In addition, care needs to be taken to employ a (reextinction) phase before reinstatement in order to be able to disentangle genuine reinstatement effects from spontaneous recovery effects. We also refer to Table 4 (see later) where a list of methodological and design recommendations for future studies is collected. In the following we have compiled a summary of possible experimental as well as biological and trait markers that may affect the reinstatement phenomenon in humans.

\section{Possible experimental boundary conditions in human reinstatement studies}

\section{Spatial manipulation of reinstatement context}

Despite the extensively studied contextual influences on reinstatement in rodents (see above), only two human single-cue studies compared reinstatement between participants receiving reinstatement USs in the same ( $\left.\mathrm{A}_{\text {acq. }} \mathrm{A}_{\text {ext. }}, \mathbf{A}_{\text {reinst. }} A_{\text {reinst.test. }}\right)$ or a different (AABA) room ("spatial reinstatement context") in which any testing took place (LaBar and Phelps 2005; Schiller et al. 2008) (see Table 2). Participants undergoing no spatial contextual change (AAAA) showed pronounced and significant reinstatement in both studies, while the AABA group exhibited no reinstatement effects (LaBar and Phelps 2005) or less pronounced response enhancement (Schiller et al. 2008), likely due to the intermixture with spontaneous recovery effects. These results nicely mirror early rodent findings (Bouton and Bolles 1979) and highlight the role of the context also in humans. However, the role of the context in humans has not been explored further in detail and largely been neglected in later studies (also see the section "Visual stimulation during reinstatement US administration" below). Recently we followed up on the role of the context in reinstatement by using cued as well as contextual conditioning in a within-subject design. In this design, the CSs are embedded in the context, which are a picture of a room (as done in, e.g., Marschner et al. 2008; Fonteyne et al. 2010). Previous studies have used this distinction of a discrete symbol (as a CS) and the surrounding environmental stimuli (as a context) to study contextual influence on fear conditioning in humans, as well (Milad et al. 2005; Kalisch et al. 2006; Milad et al. 2007). CSs were predictably followed by the US, whereas the time-point of the US administration to the context was unpredictable. Importantly, neither the CS nor the conditioned context was present during the administration of the reinstatement USs. We demonstrated more pronounced reinstatement effects toward the conditioned context as compared to the CSs using psychophysiological measures (Haaker et al. 2013b) and fMRI (Lonsdorf et al. 2014b), further adding evidence for the role of context conditioning in reinstatement. This is of importance, as human research focused exclusively on reinstatement to CSs (e.g., symbols depicted on the computer screen). Future studies in humans are needed to bridge this gap and investigate contextual boundary conditions of reinstatement in detail. However, the attenuation of the responses to the CSs may as well be a result of the presence of the conditioned context, which are a better predictor of the US after reinstatement (because reinstatement USs are not CS predicted USs, see below). This would be supported by the observation of Rescorla and Cunningham (1977 [Exp. 2]) that the presence of a stronger predictor for the US (e.g., unextinguished CS) during reinstatement test attenuates the ROF of another CS (test-CS). Of note, both CSs were unreinforced during reinstatement test.

\section{Visual stimulation during reinstatement US administration} One feature of the spatial reinstatement context is the visual input during reinstatement US administration ("the visual reinstatement context"). In contrast to studies in rodents, where a context is defined as the whole box in which the animal is placed, stimuli in human studies are presented on computer screens. However, the role of the visual stimulation on that screen during reinstatement has so far been neglected and, consequently, there is large variety between studies, which may partly explain divergent findings. Studies have used the inter-trial interval (ITI) background, the cue background (i.e., what is on the screen during CS presentation), or a neutral background (i.e., screen that has not been presented in the experiment before) as visual reinstatement context and many studies do not report what was shown (see Table 3). It can be supposed that a new association between the visual reinstatement context and the reinstatement USs might be formed which may imbue the visual context with a sense of danger. Consequently, it should have an impact on the results at test, if the ITI or the cue background is reinforced, which may be due to different associations between the CS and both contexts: The cue background is presented simultaneously with the CS during all experimental phases (except the reinstatement), whereas the CS is always absent during ITI presentation.

In addition, it needs to be considered that any change in the visual background context may evoke effects related to contextual change (e.g., renewal) and that the presentation of any conditioned context or CS during reinstatement may also induce additional processes, e.g., reacquisition. That is, if a former CS, which has already been extinguished, is presented during reinstatement US presentation, this may lead to new (or reacquired) fear conditioning toward this CS.

Furthermore, beyond visual and spatial context definitions, also temporal, interoceptive, cognitive, or social features contribute to associative contextual characteristics (Bouton 2004; Maren et al. 2013) and most of these remain unexplored to date.

Beyond these, the visual input may also trigger nonassociative cognitive processes, which might exert an impact on reinstatement effects. The reinstatement context might become aversive through the generation of uncertainty by an obvious or sensed experimental break. This contextual change may be related to subtle, but critical details in experimental design of human studies (e.g., physical reinstatement context, visual reinstatement context, subjective ratings) and might explain the enhancement 


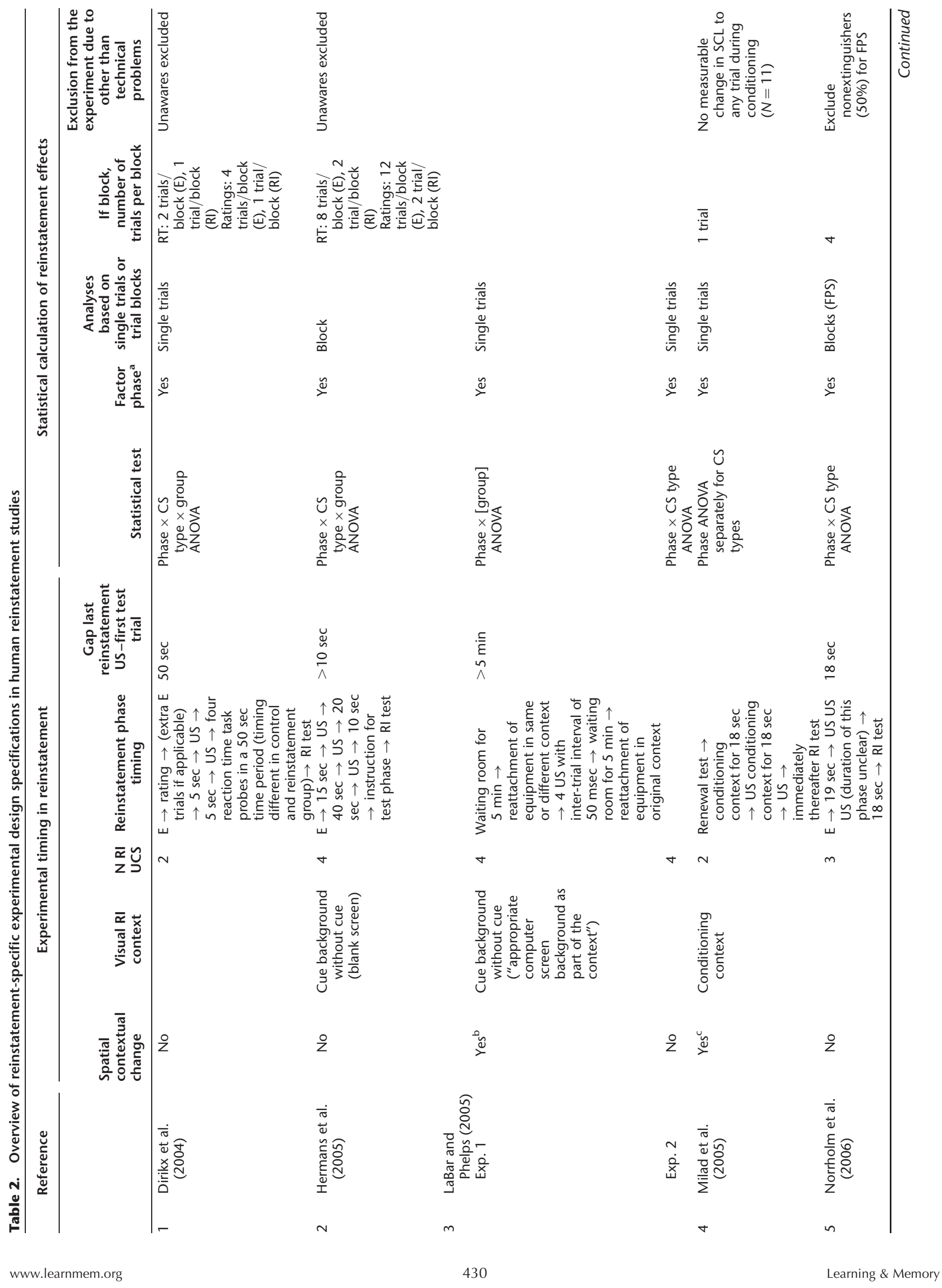




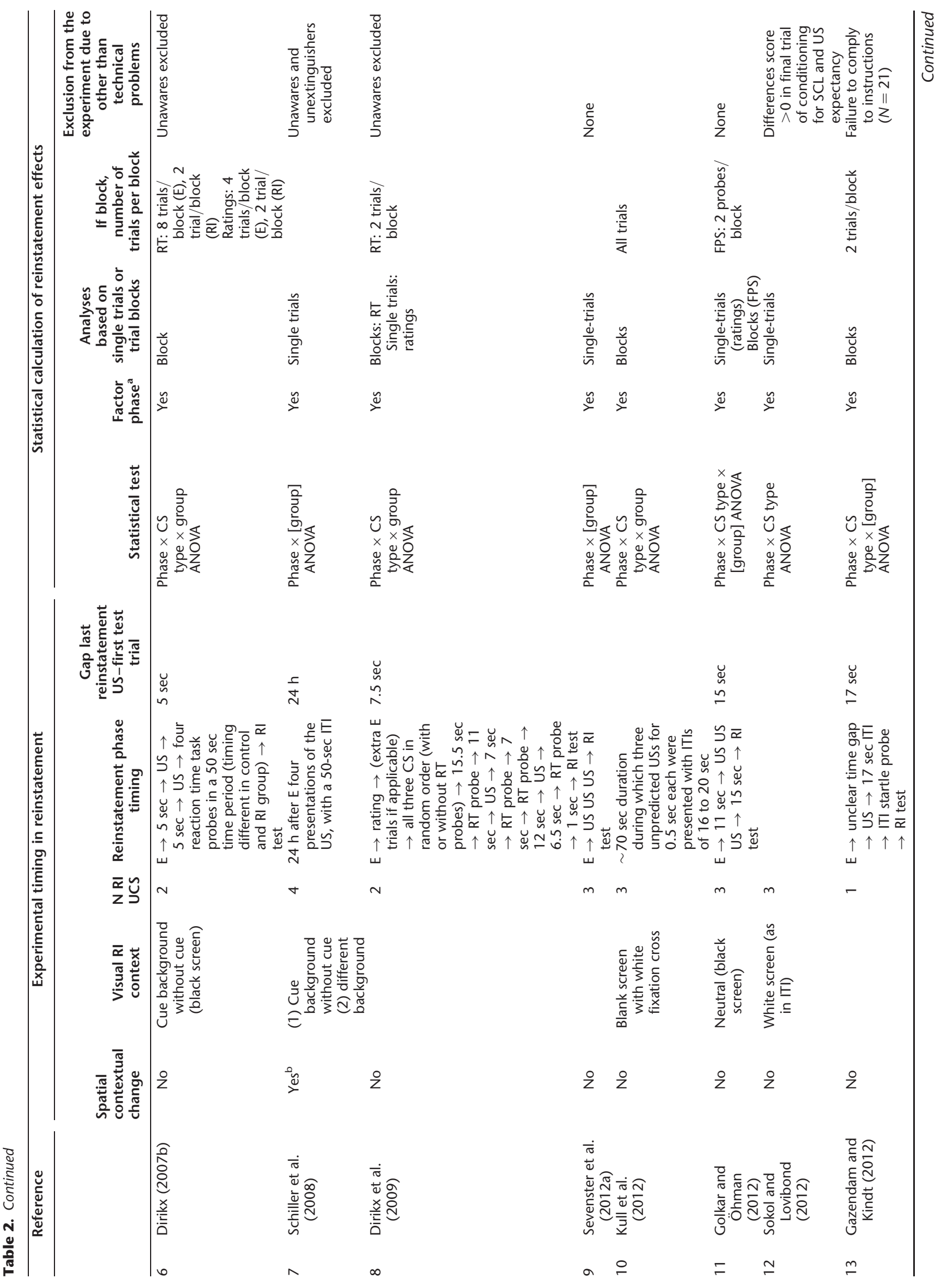




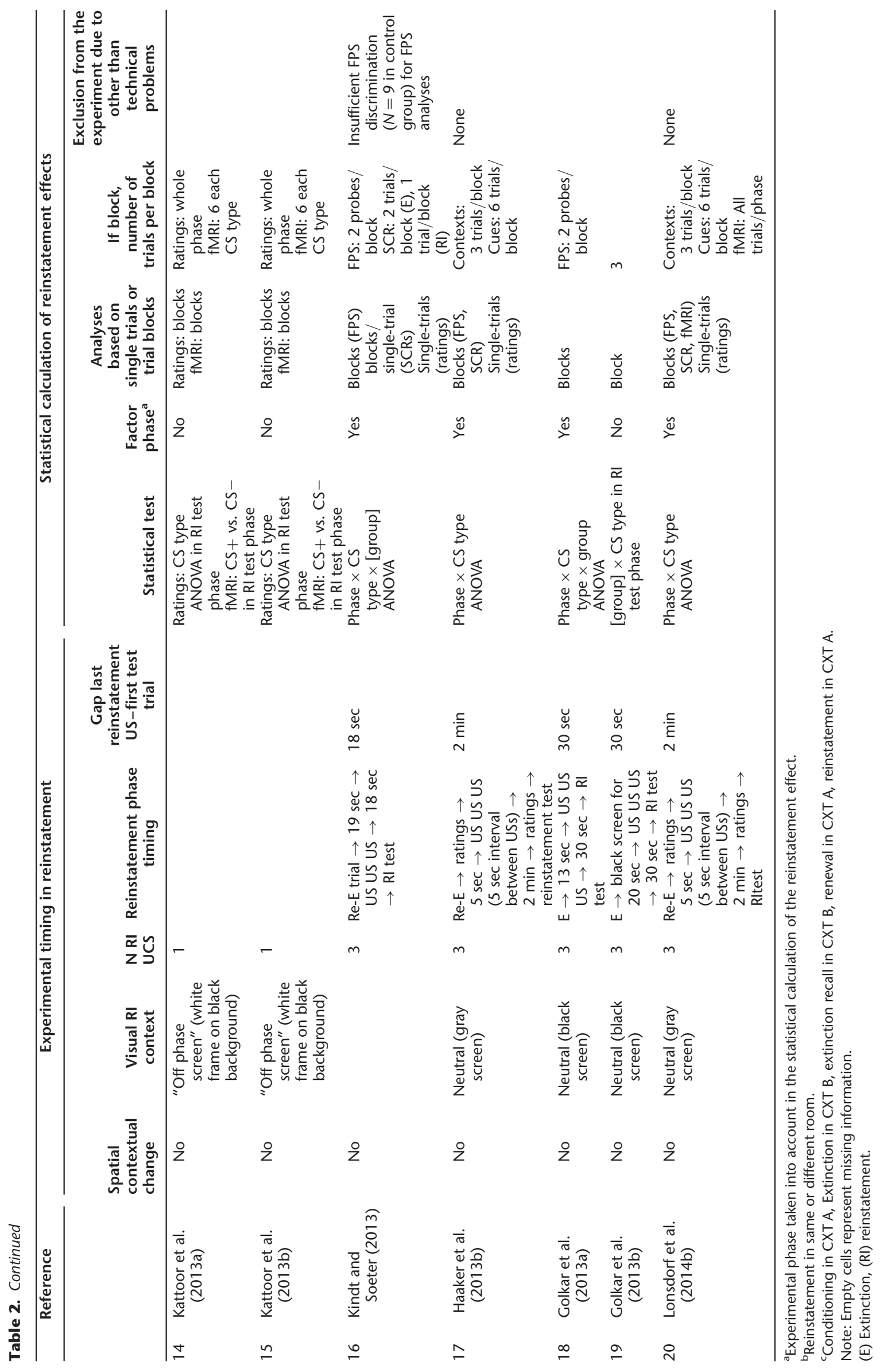


of CRs in human control groups without any US presentation (see also Table 1). If these subtle changes in context contribute to reinstatement, reinstatement might, in part, be considered as a special case of renewal.

Furthermore, the reinstatement procedure (i.e., USs that are not predicted by a CS) may induce uncertainty/unpredictability in humans by challenging the previously learned associations, that is, the CS + during reinstatement is not reliably predicting the (reinstatement) US. Experiments of Rescorla and Cunningham (1977) could show that if the reinstatement USs are signaled by a CS (reaquisition-CS, i.e., not reinstatement but reacquisition), the presence of this reaquisition-CS during reinstatement test attenuates reinstatement to another CS (test-CS, not present during the reinstatement USs). However, if only the test-CS is present, reinstatement will occur, despite the "signaled reinstatement," i.e., reacquisition. These findings can be interpreted in terms of uncertainty in humans, namely that ROF during reinstatement is abol- ished by the presence of a good predictor of the US that reduces uncertainty of US contingencies.

This uncertainty about the predictive value of the CS may be derived from contextual conditioning during reinstatement: The context gains associative value through the unexpected presentation of the USs (Pearce and Hall 1980), which possibly shifts the balance of attention from a focus on the CS toward the context (Schmajuk et al. 2007) and enhances contextual anticipatory anxiety (Grillon et al. 2006). Upon subsequent, CS-recurrence, the discrimination of the previously US-predictive CS + and nonpredictive (safe) CS - might be challenged, as their predictive value for the US is attenuated as compared to the enhanced US predictive value of the context. Supporting this idea, we found that reinstatement increases anticipatory anxiety, as indicated by response enhancement during the ITI (Haaker et al. 2013b) as well as reactivity toward the conditioned context as compared to the CSs (see above; Haaker et al. 2013b; Lonsdorf et al. 2014b).

Table 3. Overview of general sample and study characteristics in human reinstatement studies

\begin{tabular}{|c|c|c|c|c|c|c|}
\hline & Reference & $\begin{array}{c}\text { Conditioning } \\
\text { type }\end{array}$ & Experimental timing & $\begin{array}{l}\text { Reinforcement } \\
\text { ratio }\end{array}$ & US type & CS type \\
\hline 1 & Dirikx et al. (2004) & Differential & Single day $(\mathrm{C}, \mathrm{E}, \mathrm{RI})$ & $100 \%$ & Electrotactile & Faces $^{a}$ \\
\hline 2 & Hermans (2005) & Differential & Single day $(C, E, R I)$ & $100 \%$ & Electrotactile & Faces $^{\mathrm{a}}$ \\
\hline 3 & LaBar and Phelps (2005) & & & & & \\
\hline & Exp. 1 & Single-cue & Single day $(\mathrm{C}, \mathrm{E}, \mathrm{RI}$ context $)$ & $100 \%$ & $100-\mathrm{dB}$ sound & Blue square \\
\hline & Exp. 2 & Differential & Single day $(\mathrm{C}, \mathrm{E}, \mathrm{RI})$ & $100 \%$ & $100-\mathrm{dB}$ sound & Red and green squares \\
\hline 4 & Milad et al. (2005) & Differential & $\begin{array}{l}2 \text { days } \\
\text { Day } 1: \mathrm{C}, \mathrm{E} \\
\text { Day } 2: \mathrm{E}, \mathrm{E}-\mathrm{RE}, \mathrm{RN}, \mathrm{RI}\end{array}$ & $100 \%$ & Electrotactile & 2 rooms, 2 colored lights \\
\hline 5 & Norrholm et al. (2006) & Differential & $\begin{array}{l}2 \text { days } \\
\text { Day 1: C } \\
\text { Day 2: } \mathrm{E}, \mathrm{RI}\end{array}$ & $75 \%$ & Air blast & Colored lights \\
\hline 6 & Dirikx et al. (2007b) & Differential & Single day $(\mathrm{C}, \mathrm{E}, \mathrm{RI})$ & $100 \%$ & Electrotactile & Faces $^{a}$ \\
\hline 7 & Schiller et al. (2008) & Single-cue & $\begin{array}{l}3 \text { days } \\
\text { Day 1: C, E } \\
\text { Day 2: RI US } \\
\text { Day 3: } \mathrm{RI}_{\text {context }}\end{array}$ & $100 \%$ & Electrotactile & Fractal image \\
\hline 8 & Dirikx et al. (2009) & Differential & Single day $(\mathrm{C}, \mathrm{E}, \mathrm{RI})$ & $100 \%$ & Electrotactile & Faces $^{a}$ \\
\hline 9 & Sevenster et al. (2012a) & Differential & $\begin{array}{l}2 \text { days } \\
\text { Day 1:C } \\
\text { Day 2: } \mathrm{E} \text { (instructed vs. } \\
\text { noninstructed), RI }\end{array}$ & $66.6 \%$ & Electrotactile & Blue square, yellow circle \\
\hline 10 & Kull et al. (2012) & Differential & Single day $(\mathrm{C}, \mathrm{E}, \mathrm{RI})$ & $75 \%$ & Electrotactile & Neutral faces (both sexes) \\
\hline 11 & Golkar and Öhman (2012) & Differential & $\begin{array}{l}\text { Single day }(\mathrm{C}, \mathrm{E}, \mathrm{RI}) \text { or } 2 \\
\text { days: } \\
\text { Day 1: C } \\
\text { Day 2: extinction }\end{array}$ & $82 \%$ & Electrotactile & $\begin{array}{l}\text { Fearful face-background } \\
\text { color pairs }\end{array}$ \\
\hline 12 & Sokol and Lovibond (2012) & Differential & Single day $(\mathrm{C}, \mathrm{E}, \mathrm{RI})$ & $100 \%$ & $\begin{array}{l}\text { Electrotactile or } \\
\text { acoustic }\end{array}$ & Different colored squares \\
\hline 13 & Gazendam and Kindt (2012) & Differential & Single day $(\mathrm{C}, \mathrm{E}, \mathrm{RI})$ & $75 \%$ & Electrotactile & Brown circle, gray square \\
\hline 14 & Kattoor et al. (2013a) & Differential & Single day $(C, E, R I)$ & $75 \%$ & Abdom. pain & $\begin{array}{l}\text { White geometric symbols } \\
\text { in a white frame on } \\
\text { black screen }\end{array}$ \\
\hline 15 & Kattoor et al. (2013b) & Differential & Single day $(C, E, R I)$ & $75 \%$ & Aabdom. pain & $\begin{array}{l}\text { White geometric symbols } \\
\text { in a white frame on } \\
\text { black screen }\end{array}$ \\
\hline 16 & Kindt and Soeter (2013) & Differential & $\begin{array}{l}3 \text { days } \\
\text { Day 1: conditioning } \\
\text { Day 2: extinction } \\
\text { Day 3: reextinction, } \\
\text { reinstatement }\end{array}$ & $75 \%$ & Shock & Pictures of spiders \\
\hline 17 & Haaker et al. (2013b) & Differential & $\begin{array}{l}3 \text { days } \\
\text { Day 1: C } \\
\text { Day 2: E } \\
\text { Day 3: RE-E, RI }\end{array}$ & $\begin{array}{l}100 \%, 0 \% \text { and } \\
\text { unpredictable }^{k}\end{array}$ & Electrotactile & $\begin{array}{l}\text { Pictures of living rooms, } \\
\text { geometric symbols }\end{array}$ \\
\hline 18 & Golkar et al. (2013a) & Differential & Single day $(\mathrm{C}, \mathrm{E}, \mathrm{RI})$ & $67 \%$ & Electrotactile & 2 fearful male faces \\
\hline 19 & Golkar et al. (2013b) & Differential & Single day $(\mathrm{C}, \mathrm{E}, \mathrm{RI})$ & $67 \%$ & Electrotactile & 2 angry male faces \\
\hline 20 & Lonsdorf et al. (2014b) & Differential & $\begin{array}{l}3 \text { days day } 1: \mathrm{C} \text { day } 2: \mathrm{E} \\
\text { day } 3: \mathrm{RE}-\mathrm{E}, \mathrm{RI}\end{array}$ & $\begin{array}{l}100 \%, 0 \% \text { and } \\
\text { unpredictable }^{k}\end{array}$ & Electrotactile & $\begin{array}{l}\text { Pictures of living rooms, } \\
\text { geometric symbols }\end{array}$ \\
\hline
\end{tabular}


In a translational perspective, Grupe and Nitschke (2013) described uncertainty as a key factor for clinically relevant anxious behavior. According to their model, uncertainty leads to the persistence of previously learned responses and decreases the ability to inhibit defensive responses toward safety signals. This might explain a reduced discrimination of the CS + and the CS - following reinstatement, which is reflected in the high frequency of generalized reinstatement in humans.

\section{Experimental timing}

Rodent studies have demonstrated that timing of reinstatement US presentation with respect to reinstatement context onset has an impact on the degree of reinstatement (Richardson et al. 1999), an experimental detail which has not been given attention in human work. Furthermore, experimental phases (acquisition, extinction, reinstatement, reinstatement test) usually take place on distinct days while in human studies they often follow upon each other immediately (see Table 2), which hampers translation between species. Furthermore, there is increasing evidence that experimental timing has an impact on ROF in humans (e.g., Huff et al. 2009; Golkar and Öhman 2012) and animals (Myers et al. 2006; but see Schiller et al. 2008; Woods and Bouton 2008) and may rely on different molecular mechanisms (Cain et al. 2005). Separating conditioning and extinction learning in time allows for memory consolidation and thus represents a more naturalistic model for clinical relapse as usually time elapses between a traumatic event, CBT, and relapse.

Still, few reinstatement studies have separated experimental phases (acquisition-extinction, extinction-reinstatement US administration, reinstatement US administration-reinstatement test) in time. In most cases, reinstatement (both reinstatement US administration and test) was tested immediately following extinction, which was delayed $24 \mathrm{~h}$ or immediately followed upon acquisition. Reinstatement after 24-h-delayed extinction
(Norrholm et al. 2006; Golkar and Öhman 2012; Sevenster et al. 2012a [uninstructed extinction group]) was more pronounced as compared to reinstatement following immediate extinction (unmasked stimuli; Golkar and Öhman 2012). Others (Milad et al. 2005; Schiller et al. 2008) have separated reinstatement testing (preceded by the reinstatement US on the same day) $24 \mathrm{~h}$ after extinction learning, but both studies used immediate extinction after acquisition in the first place. In addition, the results of both studies are not unequivocally attributable to reinstatement effects as the reinstatement test followed immediately upon a recall as well as a renewal test in one study (Milad et al. 2005), and it was intermixed with spontaneous recovery and orienting responses in the other study as no extinction or a second extinction (reextinction) phase immediately preceded reinstatement (Schiller et al. 2008). The use of no-reinstatement US control groups in these studies would have enhanced interpretability of these data.

Recently, there seems to be a trend toward separating acquisition, extinction, extinction recall/reextinction, and reinstatement in time (Haaker et al. 2013; Kindt and Soeter 2013; Lonsdorf et al. 2014b), and there is preliminary evidence that reinstatement might occur even after a long time delay of $1 \mathrm{mo}$ (Kindt et al. 2009) or $1 \mathrm{yr}$ (Schiller et al. 2010) after reactivation/ reconsolidation and successful extinction. However, these tests do not represent pure reinstatement effects as these were contaminated by the drug vs. placebo manipulations (Kindt et al. 2009) and an intermixture of reinstatement effects with spontaneous recovery (Schiller et al. 2010) may bias the results.

In addition, timing within the phase of reinstatement US administration varies widely (see Table 3 ). That is, for instance, the time gap from the last reinstatement US administration to the first test trial, the occurrence of ratings, or other tasks (e.g., RT tasks, reminder CSs) before the first reinstatement test trial. In particular, ratings or brakes may be perceived as indicators of contextual change and induce uncertainty (Pineño and Miller 2004). Most

Table 3. Continued

\begin{tabular}{|c|c|c|c|c|c|c|c|}
\hline & \multirow[b]{2}{*}{ Reference } & \multirow[b]{2}{*}{$\begin{array}{l}\mathrm{NCS}+/ \\
\mathrm{NCS}-\end{array}$} & \multicolumn{3}{|c|}{ Number of trials } & \multicolumn{2}{|r|}{ Instruction } \\
\hline & & & $\mathrm{C}\left(\mathrm{CS}+/ \mathrm{CS}^{-}\right)$ & $\mathrm{E}(\mathrm{CS}+/ \mathrm{CS}-)$ & $\mathrm{RI}\left(\mathrm{CS}+/ \mathrm{CS}^{-}\right)$ & A & E \\
\hline 1 & Dirikx et al. (2004) & $1 / 3$ & $8 / 8,8,8$ & $12 / 12,12,12^{b}$ & $2 / 2$ & $Y_{e s}^{c}$ & No \\
\hline 2 & Hermans (2005) & $1 / 1$ & $12 / 12$ & $36 / 36$ & $2 / 2$ & Yes $^{c}$ & No \\
\hline \multirow[t]{3}{*}{3} & LaBar and Phelps (2005) & & & & & & \\
\hline & Exp. 1 & $1 / 0$ & 4 & 8 & 8 & No & No \\
\hline & Exp. 2 & $1 / 1$ & $4 / 4$ & $8 / 8$ & 8,8 & No & No \\
\hline 4 & Milad et al. (2005) & $1 / 1$ & $5 / 5$ & $10 / 10$ or none & $5 / 5$ & Yes $^{\mathrm{d}, \mathrm{e}}$ & Reminder $^{f}$ \\
\hline 5 & Norrholm et al. (2006) & $1 / 1$ & $16 / 16$ & $24 / 24$ & 4,4 & Yes $^{g}$ & Reminder ${ }^{f}$ \\
\hline 6 & Dirikx et al. (2007b) & $1 / 3$ & $8 / 8,8,8$ & $12 / 12,12,12$ & 2,2 & Yes $^{c}$ & No \\
\hline 7 & Schiller et al. (2008) & $1 / 0$ & 8 & 16 & 20 & $Y_{e s}^{d}$ & No \\
\hline 8 & Dirikx et al. (2009) & $1 / 2$ & $8 / 8,8$ & $12 / 12,12^{b}$ & 2,2 & Yes $^{g}$ & Yes \\
\hline 9 & Sevenster et al. (2012a) & $1 / 1$ & $6 / 6$ & $16 / 16$ & 8,8 & Yes $^{9}$ & $\begin{array}{l}\text { Yes }(N=24) \text {, no } \\
\quad(N=25)\end{array}$ \\
\hline 10 & Kull et al. (2012) & $1 / 1$ & $4 / 4$ & $6 / 6$ & 2,2 & Yes $^{c}$ & Yes \\
\hline 11 & Golkar and Öhman (2012) & $2 / 2$ & $9,9 / 9,9$ & $12,12, / 12,12$ & $4,4,4,4$ & Yes $^{\mathrm{d}}$ & No \\
\hline 12 & Sokol and Lovibond (2012) & $1 / 2$ & $3 / 3,3$ & $6 / 6,6$ & $1 \times A ; 1 \times B$ & NA & NA \\
\hline 13 & Gazendam and Kindt (2012) & $1 / 1$ & $8 / 8$ & $12 / 12$ & $6 / 6$ & Yes $^{\mathrm{d}}$ & No \\
\hline 14 & Kattoor et al. (2013a) & $1 / 1$ & $16 / 16$ & $12 / 12$ & $6 / 6$ & & \\
\hline 15 & Kattoor et al. (2013b) & $1 / 1$ & $16 / 16$ & 12,12 & $6 / 6$ & & \\
\hline 16 & Kindt and Soeter (2013) & $1 / 1$ & $8 / 8$ & $12 / 12$ & $8 / 8$ & Yes $^{h, i}$ & Reminder $^{f}$ \\
\hline 17 & Haaker et al. (2013) & & $\begin{array}{l}9 \text { each CXT; } 18 \\
\text { each Cue }\end{array}$ & $\begin{array}{l}\text { Extinction and reextinction each } 6 \\
\text { each CXT, } 12 \text { each Cue }\end{array}$ & $\begin{array}{l}6 \text { each CXT, } 12 \\
\text { each Cue }\end{array}$ & No & No \\
\hline 18 & Golkar et al. (2013a) & $1 / 1$ & $9 / 9$ & $12 / 12$ or $24 / 24$ & $4 / 4$ & Yes $^{9}$ & No \\
\hline 19 & Golkar et al. (2013b) & $1 / 1$ & $6 / 6$ & $6 / 6$ & $6 / 6$ & $Y_{e s}^{d}$ & No \\
\hline 20 & Lonsdorf et al. (2014b) & & $\begin{array}{l}9 \text { each CXT; } 18 \\
\text { each Cue }\end{array}$ & $\begin{array}{l}\text { Extinction and reextinction each } 6 \\
\text { each CXT } 12 \text { each Cue }\end{array}$ & $\begin{array}{l}6 \text { each CXT, } 12 \\
\text { each Cue }\end{array}$ & No & No \\
\hline
\end{tabular}


problematic, these experimental details are often reported only rudimentarily which hampers an evaluation of their influence.

Future studies should report this information in detail and consider the impact of experimental timing. In particular, to pro- vide a plain measure of reinstatement, extinction/reextinction should be employed before the reinstatement manipulation to separate genuine reinstatement processes from spontaneous recovery and orienting. Further, caution is warranted in multiple

Table 3. Continued

\begin{tabular}{|c|c|c|c|c|c|c|c|c|c|c|}
\hline & \multirow[b]{2}{*}{ Reference } & \multicolumn{4}{|c|}{ Number of participants } & \multirow[b]{2}{*}{ Age (yr) } & \multicolumn{4}{|c|}{ Dependent measurements } \\
\hline & & RI group(s) & $\begin{array}{l}\text { Control } \\
\text { group }\end{array}$ & Male: female & Unaware & & $\begin{array}{l}\mathrm{SCR} / \\
\mathrm{SCL}\end{array}$ & FPS & Ratings & Other \\
\hline 1 & Dirikx et al. (2004) & 17 & 16 & $19: 14$ & 13 & & & & US, Fear, Val & RT \\
\hline 2 & Hermans (2005) & 14 & 14 & $0: 28$ & 2 & & & & US, Fear, Val & RT \\
\hline \multirow[t]{2}{*}{3} & $\begin{array}{l}\text { LaBar and Phelps } \\
\text { (2005) }\end{array}$ & & & & & & & & & \\
\hline & Exp. 1 & $\begin{array}{l}20 \text { AAAA } \\
23 \text { AABA }\end{array}$ & None & $15: 28$ & & Range $18-22$ & SCR & & & \\
\hline & Exp. 2 & 27 & None & $11: 16$ & & Range $18-22$ & SCR & & & \\
\hline 4 & Milad et al. (2005) & 20 & None & $20: 21$ & & Mean 25.7 & $\mathrm{SCL}$ & & & \\
\hline 5 & $\begin{array}{l}\text { Norrholm et al. } \\
\text { (2006) }\end{array}$ & 22 & 22 & $20: 25$ & & Mean 29.4 & & & US & \\
\hline 6 & Dirikx et al. (2007b) & 16 & 17 & $\begin{array}{l}\text { RI: } 1: 15 \\
\text { Control: } \\
2: 15\end{array}$ & 11 & Mean: 18,61 & & & US, Fear, Val & RT \\
\hline 7 & Schiller et al. (2008) & $\begin{array}{l}18 \text { AAAA } \\
16 \text { AABA }\end{array}$ & None & $16: 18$ & 6 & Range $18-27$ & SCR & & & \\
\hline 8 & Dirikx et al. (2009) & 21 & 21 & & 6 & & & & US, Fear, Val & RT \\
\hline 9 & $\begin{array}{l}\text { Sevenster et al. } \\
\quad(2012 a)\end{array}$ & 40 & None & $9: 31$ & & Mean 21.75 & SCR & & & \\
\hline 10 & Kull et al. (2012) & 28 & 27 & $13: 42$ & 0 & Mean 25.2 & SCR & & US & \\
\hline 11 & $\begin{array}{l}\text { Golkar and Öhman } \\
\text { (2012) }\end{array}$ & 27 & None & $8: 19$ & & Mean 24.9 & & & US & \\
\hline 12 & $\begin{array}{l}\text { Sokol and Lovibond } \\
\text { (2012) }\end{array}$ & 82 & & $34: 48$ & & Mean 19.41 & $\mathrm{SCL}$ & & US expectancy & \\
\hline 13 & $\begin{array}{l}\text { Gazendam } \\
\text { and Kindt (2012) }\end{array}$ & 48 & None & $\begin{array}{l}\text { Worry:4:19; } \\
\text { no } \\
\text { worry:7:18 }\end{array}$ & & Mean 22.2 & & & $\begin{array}{l}\text { US expectancy } \\
\text { (but not for } \\
\text { RI) }\end{array}$ & \\
\hline 14 & $\begin{array}{l}\text { Kattoor et al. } \\
\text { (2013a) }\end{array}$ & 21 & None & $15: 6$ & & Mean 24.06 & & & US, tens, val & BOLD \\
\hline 15 & $\begin{array}{l}\text { Kattoor et al. } \\
(2013 b)\end{array}$ & $30^{\mathrm{h}}$ & None & $15: 15$ & & Mean 24.53 & & & & $\begin{array}{l}\text { BOLD for } \\
\text { cerebellum }\end{array}$ \\
\hline 16 & $\begin{array}{l}\text { Kindt and Soeter } \\
\text { (2013) }\end{array}$ & $\mathrm{j}$ & None & $13: 27$ & & Range $18-33$ & SCR & & US & \\
\hline 17 & Haaker et al. (2013b) & 93 & None & $23: 70$ & 19 & Range $20-46$ & SCR & & Fear & \\
\hline $\begin{array}{l}18 \\
19\end{array}$ & $\begin{array}{l}\text { Golkar et al. (2013a) } \\
\text { Golkar et al. (2013b) }\end{array}$ & $\begin{array}{c}57 \\
\text { Extinction }\end{array}$ & None & $\begin{array}{c}38: 19 \\
55: 0\end{array}$ & $\begin{array}{l}0 \\
4\end{array}$ & $\begin{array}{l}\text { Mean: } 24 \\
\text { Mean: } 25.2\end{array}$ & SCR & & & \\
\hline & & $\begin{array}{l}\text { groups: } \\
\text { Direct: } \\
(N=20) \\
\text { Vicarious } \\
(N=16) \\
\text { Vicarious } \\
\text { reinf. } \\
(N=19)\end{array}$ & & & & & & & & \\
\hline 20 & $\begin{array}{l}\text { Lonsdorf et al. } \\
\quad(2014 b)\end{array}$ & $\begin{array}{l}20 \text { (sample } \\
\text { 1) } \\
19 \text { (sample } \\
\text { 2) }\end{array}$ & None & $39: 0$ & $\begin{array}{l}\text { Sample } \\
\text { 1:5 } \\
\text { Sample } \\
2: 3\end{array}$ & Mean:29.0 & SCR & & Fear & BOLD \\
\hline
\end{tabular}

${ }^{\text {a }}$ Selected individually to be neutral.

${ }^{\mathrm{b}}$ Add a further eight extinction trials for each $\mathrm{CS}$ if not fully extinguished.

'One stimulus will always be followed by the US.

${ }^{\mathrm{d} C}$ Conditioning in CXT A, extinction in CXT B, extinction recall in CXT B, renewal in CXT A, reinstatement in CXT A.

eparticipants instructed to look for contingencies.

${ }^{f}$ Remember what you have learned/you may or may not be shocked.

${ }^{\text {g}}$ One out of two will be sometimes/most of the time followed by the US.

hample overlaps with the sample in Kattoor et al. (2013a).

'If there is a US, it will occur at the end of a picture.

iUnclear as only the control group is considered here (not specified).

${ }^{\mathrm{k}}$ Three different conditions: predictable with $100 \%$ reinforcement of the discrete cue but $0 \%$ for the context, unpredictable with unpredictable US presentations mainly during the context and rarely during the cue, and a safe condition (no US to either cue or context).

Note: Empty cells represent missing information.

(C) Conditioning, (E) extinction, (E-RE) extinction recall, (RN) renewal, (RI US) reinstatement US presentation, (RI) reinstatement test, ( $\mathrm{RI}_{\text {context }}$ ) reinstatement test with and without contextual change, (RA) reacquisition. 
day paradigms that use multiple US calibrations as this procure may function in itself as reinstatement.

\section{Reinstatement induces only very transient effects in healthy participants}

While a differential rodent study has shown very slow extinction of the reinstatement effect (Dirikx et al. 2007a), the response enhancement in humans seems to be very transient and manifests as, on average, one to three single enhanced responses following reinstatement US administration in FPS (Gazendam and Kindt 2012; Sevenster et al. 2012a; Kindt and Soeter 2013), SCL (Milad et al. 2005), and SCRs (Kindt and Soeter 2013), and up to four single enhanced trials in US expectancy ratings (Norrholm et al. 2006; Gazendam and Kindt 2012; Golkar and Öhman 2012; Sevenster et al. 2012a; Kindt and Soeter 2013 [normal extinction $>$ instructed extinction]). To date, a single human study showed statistically that reinstatement effects in fear and US-expectancy ratings did not survive 16 unreinforced CS + and CS - presentations (Hermans et al. 2005). As returning CRs are typically only evident in a few trials, reinstatement effects might be particularly susceptible to stimulus sequence effects. For instance, it is likely that, if the first CS after reinstatement is an unreinforced CS+, some participants may expect a US to the CS-, which may in part explain nondifferential ROF in comparison to sequences where the first trial is an unreinforced CS - . This may be particularly pronounced in paradigms using a 100\% reinforcement ratio. Therefore, stimulus sequences following reinstatement need to be carefully balanced and reported in detail.

While in healthy populations the reinstatement effect is very transient (i.e., lasts only for a limited number of test trials), studies of fear learning and reinstatement with ecologically valid USs in patient populations are eagerly awaited. Until then, it can only be hypothesized that reinstatement effects in patients might be more stable over time and of different quality (e.g., more generalized). Furthermore, in patients a very brief induction of fear might be sufficient induce full blown clinical relapse and avoidance behavior.

\section{Number of extinction trials/amount of extinction success}

According to Bouton (2004), ROF represents the recurrence of the CR to an extinguished CS, most likely due to an underlying association of the CS with the US. Thus, a crucial determinant of the degree of ROF following reinstatement might be the strength of the corresponding CS-US association (fear memory) as opposed to the inhibitory CS-no US association (extinction memory). The balance of one over the other might be affected by the number of conditioning and/or extinction trials as well as their relative proportion. In support of this, rodent work on renewal suggests that massive extinction learning attenuates renewal effects as compared to moderate extinction (Denniston et al. 2003).

It is important to note that some studies have excluded "nonextinguishers" or included additional extinction trials for nonextinguishers (see Table 3) to achieve comparable end-point extinction performance or, in other words, associative memory strength. The impact of this has, however, not yet been investigated. We performed an exploratory comparison of studies showing differential or generalized reinstatement in different dependent measures with respect to the trial numbers in conditioning and extinction. ${ }^{4}$ This suggested that a higher number of extinction, but not conditioning, trials was overrepresented in studies reporting differential reinstatement. However, a study statistically comparing the role of different numbers of extinction trials as well as different CS durations during extinction (Golkar et al. 2013a) found no impact of the amount of extinction on the degree of the reinstated FPS. In addition, the reduction of fear as well as the fear level at the end of a therapy was found to have no impact on therapeutic outcome (Craske et al. 2008).

Future studies should address how the degree of fear acquisition and extinction learning influences the reinstatement of fear. Additionally, the proportion of ROF related to the expression of fear memory at the outset of extinction may offer a supplementary index of reinstatement. As resistance to reinstatement might be interpreted as an indicator of a predominant extinction memory trace, studies focusing on this might provide important clues for the enduring endeavor in finding ways to strengthen extinction memories and enhance CBT efficacy.

\section{Type of CS and US stimulation}

Studies have used neutral pictures, such as geometrical shapes, neutral faces, colored lights, as well as fear-relevant pictures (fearful/angry faces, spiders) as CSs (see Table 2). Studies have so far almost exclusively focused on discrete CSs and only two studies (Haaker et al. 2013b; Lonsdorf et al. 2014b) investigated reinstatement to CS (geometric shapes) and conditioned contexts (pictures of rooms on which the geometric shapes were superimposed) in a within-subject design. As described above, the context seemed to be more affected by the reinstatement as compared to the CSs in two independent samples.

While the type of CS varies widely, the most commonly used US-type in human fear conditioning and reinstatement is electrotactile stimulation, but also a loud tone, an air blast to the throat, or visceral pain has been employed (see Table 2). USs types differ in their inherent aversiveness (Glenn et al. 2012; Sokol and Lovibond 2012) and the choice of US type might be critical as only CRs to a conditioned predictor of an electrotactile US, but not to a human scream, were found to be correlated with trait anxiety (Glenn et al. 2012).

The majority of the studies used 100\% reinforcement (min $66.6 \%$; see Table 2) and there does not seem to be a relationship between different reinforcement ratios and the outcome of reinstatement. Also, in human studies, nearly all have used identical US types during fear acquisition and reinstatement. Of note, reinstatement has also been observed after presenting a different US type during reinstatement ( $\mathrm{US}_{\text {reinst. }}$ ) as compared to fear acquisition $\left(\mathrm{US}_{\mathrm{acq}}\right.$ ) in rodents (different intensity [Kim and Richardson 2007], qualitatively different [Rescorla and Heth 1975]), and in humans (noise and electrotactile [Sokol and Lovibond 2012]). Of note, human participants expected occurrence of the US reinst. $_{\text {. }}$ and not the $\mathrm{US}_{\text {acq. }}$ during test following the reinstatement manipulation (Sokol and Lovibond 2012). This demonstrates that aversive experiences other than the $\mathrm{US}_{\text {acq. }}$ are capable of mediating ROF. As aversive or stressful life events affect relapse risk in anxiety related disorders (Wade et al. 1993) this might be of particular clinical relevance. In support of this, a recent rodent study showed that the presentation of an unextinguished CS + (predictive of the US during acquisition) can reinstate the CR to an extinguished CS + (Halladay et al. 2012). Earlier series of experiments (e.g., Rescorla and Heth 1975 [Exp. 2]) have observed this induction of reinstatement as well, albeit they did not observe strong evidence for this manipulation as compared to reinstatement through US presentation.

This induction of reinstatement may be related to the aforementioned observation of mediated conditioning in ROF (see

${ }^{4}$ We collapsed different types of dependent measurements used in each study and compared the trial number between the reports of differential and generalized reinstatement. 
above), meaning that reinstatement may be due to a common association of the extinguished CS and the US, as well as between the US and the unextinguished CS+ (used to reinstate the CR).

In conclusion, reinstatement does not necessarily increase the expectation of the USs $s_{\text {acq. }}$ And the observation of ROF following a different aversive event than the actually feared event dramatically enhances the chances for ROF in everyday life.

\section{Instruction vs. noninstruction}

Of note, the majority of reinstatement studies used instructed acquisition (see Table 2), mostly providing explicit information that "one stimulus will always/sometimes be followed by the US," while fewer studies told participants "to look for contingencies between the stimuli and the US." As instructed and uninstructed conditioning might tap different processes, this may translate into different behavioral and neural correlates (Mechias et al. 2010; Maier et al. 2012).

The extinction learning phase, in turn, has mostly been uninstructed, likely because it immediately has followed upon the acquisition phase (see Table 2) and in a few cases participants were told "to remember what they had learned during acquisition" or that they "might be or not be" shocked. A direct comparison of reinstatement effects following instructed acquisition and 24-h-delayed instructed or uninstructed extinction (Sevenster et al. 2012a) found reinstatement in FPS in both the instructed and the noninstructed extinction group. In SCRs and US expectancy ratings responding was, however, completely abolished during instructed extinction and did not return after reinstatement. In addition, reinstatement of SCRs was also attenuated during another type of social learning, namely observational extinction (e.g., after regular fear conditioning, participants observed a confederate undergoing extinction) as compared to direct extinction (Golkar et al. 2013b). While instructed and observational extinction might attenuate ROF, explicit tests of the effect of instructed vs. uninstructed acquisition are still awaited. In addition, new data from our group show that reinstatement, assessed by SCRs, FPS, fear, and US expectancy ratings, is equally pronounced to a CS that was actually predictive of the US and to a CS that was said to be predictive of the US, whereas it in fact was never followed by the US during acquisition (Mertens, Kuhn et al., in prep.).

\section{Individual and biological differences}

In addition to experimental boundary conditions, individual differences may be related to the observation of generalized or differential reinstatement effects. In addition, pharmacological manipulations affecting ROF as well as the neural correlates have just begun to be studied.

\section{Self-reported anxiety}

Different studies from Merel Kindt's lab suggest that reinstatement of the CS - responses is correlated with trait anxiety (Kindt et al. 2009 [in FPS in a propranolol-no reactivation group only]; Kindt and Soeter 2013 [in SCR]; Soeter and Kindt 2010 [in SCR in the placebo group only]). Interestingly, in the Kindt et al. (2009) study, the only experimental group showing this correlation was characterized by significantly higher trait anxiety scores than the other experimental groups. In addition, they have shown that accounting for trait anxiety as a covariant in the reinstatement analysis (SCRs) changed results from generalized to differential reinstatement effects (Kindt and Soeter 2013). Our own data (unpublished findings) support these preliminary findings in showing that a CS $+/ C S-$ discrimination index after reinstatement correlates negatively with state anxiety, which is driven by enhanced CS - responses in the high state anxiety group and by a CS+-specific increase in the low state anxiety group.

Vervliet et al. (2013b) suggests two mechanistic explanations for this observation: anxious individuals may be prone to generalization (Lissek et al. 2010) and/or exhibit profound contextual anxiety (Grillon 2002). In addition, highly anxious individuals might be more prone to the perception of uncertainty after reinstatement, which might be reflected in the disinhibition of the CR to signals of safety. Beyond individual traits, the experimental induction of worrying by presenting catastrophic questions regarding the participants' tolerance for the US between acquisition and immediate extinction impaired extinction and thus also enhanced ROF after reinstatement as assessed by US expectancy ratings but not FPS (Gazendam and Kindt 2012).

In sum, anxious individuals might be more prone to display stronger and less differential reinstatement, a picture that presents similarly for other return of fear phenomena (for review, see Boschen et al. 2009). Furthermore, as noted above, the choice of US type might also be critical as only the CR to an electrotactile, but not to a scream US, was correlated with trait anxiety during fear learning (Glenn et al. 2012).

\section{Awareness}

Some reinstatement studies provide information about participants CS/US contingency awareness following acquisition and most of these studies have excluded unaware participants (see Table 3). Exclusion was based on post-experimental interviews or nondifferential SCRs during acquisition (taken to indicate lack of conditioning success). In particular the latter might affect whether response enhancement following reinstatement is generalized or differential as participants exhibiting less differential responding during acquisition might also show less differential reinstatement. The effect of excluding or including unaware participants has, however, not been systematically studied to date with respect to reinstatement. A single study has experimentally manipulated awareness of the CSs during extinction learning through backward masking and observed differential reinstatement in FPS (compare experimental timing section) (Golkar and Öhman 2012).

\section{Reconsolidation}

Reconsolidation is a process whereby previously consolidated memories can be reactivated and again rendered sensitive to disruption (e.g., Nader et al. 2000). Extinction training within the reconsolidation time-window following reactivation was found to abolish reinstatement (though intermixed with spontaneous recovery, see above [Schiller et al. 2010]). However, reinstatement was observed in different follow-up studies that tried to replicate these findings using FPS, SCR, and US-expectancy ratings (Soeter and Kindt 2011 [Exp. 2]; Golkar et al. 2012; Kindt and Soeter 2013). Reinstatement, similar to reactivation, induces retrieval of the CS-US memory trace. Instead of using a single CS reactivation trial, using a single US reactivation trial might also render the CS-US associative memory labile and sensitive to disruption (for discussion, see Lonsdorf et al. 2014a). To date this is highly speculative and, to our knowledge, this hypothesis has not been tested explicitly in rodents or humans and it would be interesting if protein-synthesis inhibition following reinstatement US administration would disrupt the context-US association that is thought to mediate the reinstatement effect. This relates to the report by Deębiec et al. (2006) who showed that directly reactivated memories become labile and consequently their consolidation becomes susceptible to protein-synthesis inhibition while indirectly 
reactivated (i.e., associated through second-order conditioning) memories do not.

\section{Pharmacological manipulations}

In rodents, reinstatement can occur after biological manipulations such as systemic epinephrine (Morris et al. 2005) or adrenocorticotropin administration (Richardson et al. 1984) as well as arousal-triggering electrical stimulation of the amygdala (Kellett and Kokkinidis 2004). In humans, some biological candidate systems have been investigated, namely the adrenergic system and the endogenous cannabinoid system. Antagonism of $\beta$-adrenergic receptors (using propranolol) $24 \mathrm{~h}$ after conditioning (and $24 \mathrm{~h}$ before extinction) does not attenuate response enhancement after reinstatement (Kindt et al. 2009). However, responses are not enhanced when a CS reactivation trial precedes the noradrenergic manipulations described above (Kindt et al. 2009; Soeter and Kindt 2011 [Exp. 1]) or if the reactivation violates the expected US occurrence (e.g., prediction error) (Sevenster et al. 2012b; 2013).

Noradrenaline reuptake inhibition (through reboxetine) directly after extinction did not affect reinstatement 1 wk later in psychophysiological measurements but seemed to lead to activation of the fear network in fMRI (Lonsdorf et al. 2014a). Administration of cannabidiol, which increases levels of the endogenous cannabinoid anandamide prior and post extinction learning reduced differential SCRs to CSs after reinstatement (Leweke et al. 2012) and decreased US expectancy to the CSs as well as their surrounding context after reinstatement when given only after extinction learning (Das et al. 2013). Dopaminergic enhancement after extinction learning was found to reduce reinstatement of conditioned contexts in humans (Haaker, Lonsdorf, Fadai, and Kalisch, in prep.) as well as in mice (Haaker et al. 2013a). These data suggest that also in humans biological manipulations have an impact on reinstatement but the exact underlying pathways remain unstudied.

\section{Neural correlates of reinstatement}

Studies of the neural system mediating reinstatement in rodents observed a critical role of the amygdala and hippocampus for the ROF through reinstatement (Frohardt et al. 2000) (amygdala [Laurent and Westbrook 2010) and hippocampus [Wilson et al. 1995]). In particular, as both regions have been implicated in the processing of contextual stimuli and other ROF phenomena in rodents (Quirk and Mueller 2008; Maren 2011; Maren et al. 2013) these findings line up with the important role of the context in reinstatement (see above).

The first study addressing the neural underpinnings of reinstatement in humans found reinstatement to be abolished in patients with hippocampus lesions (LaBar and Phelps 2005). Only recently, studies emerged that investigated the neural network underlying reinstatement effects using functional imaging. Two studies using a visceral pain US and a cue-conditioning paradigm found trend-wise differential $(\mathrm{CS}+>\mathrm{CS}-$ ) hemodynamic responses after reinstatement in the parahippocampus (Kattoor et al. 2013a) and the cerebellum (Kattoor et al. 2013b). An additional study using cued and contextual conditioning found significant and widespread (anterior) hippocampus activation to the contexts in the critical reinstatement test (after $>$ before reinstatement) in two independent samples (Lonsdorf et al. 2014b). Furthermore, significant differential responses to the conditioned contexts were observed in the amygdala and the dmPFC after reinstatement, mirroring previous animal work and once again highlighting the role of the context-responsivity in reinstatement. Enhanced responses to the cued stimuli, in turn, were observed in the subgenual ACC/vmPFC, an area commonly impli- cated in fear inhibitory and regulatory processes (Lonsdorf et al. 2014b), which might be an epiphenomenon of the combined context and cue-conditioning design.

\section{Summary and future perspectives}

From this overview, it becomes clear that research on the reinstatement phenomenon in humans is still in its infancy. In this review, we have provided a detailed overview for the existing human studies (see also Tables 1-3) and compiled a number of possible experimental boundary conditions that we believe may impact on the degree of ROF following reinstatement.

There is a large variety with respect to experimental design and data analysis, and consequently results are currently difficult to interpret and put into context. To foster fruitful future research and raise awareness with respect to some critical methodological considerations, Table 4 is meant as a guide for future studies. Table 4 lists the major recommendations given throughout the review, both with respect to study design and to data analysis.

To round our review off, the probably most puzzling and unanswered questions in human reinstatement research is what factors contribute to generalized, differential, or absent reinstatement effects or even reinstatement in no-reinstatement US control groups and how this relates to clinical populations. The experimental boundary conditions, state, trait, or biological factors that may contribute to these different observations in humans have not yet been systematically evaluated and it cannot be excluded that multiple mechanisms may interact to determine the degree and quality of reinstatement.

Currently, we do not know under which conditions reinstatement in humans occurs and whether theories derived from

Table 4. Methodological recommendation for future studies

\section{Design}

- Include an extinction or additional extinction (reextinction) phase right before the reinstatement manipulation to allow for a clean measure of reinstatement unconfounded by sensitization or other ROF processes (i.e., spontaneous recovery effects).

- To obtain a clean measure of reinstatement, consider that any contextual change during or after reinstatement may induce renewal processes and employ appropriate control groups.

- Consider the use of additional and appropriate control stimuli to allow disentangling of reinstatement from other ROF processes.

- It is highly recommended to use appropriate control groups (e.g., no-reinstatement US control group and other controls depending on the specific experimental design).

- Include exact descriptions of the type of visual stimulation, other experimental phases (e.g., ratings), and timing during reinstatementUS administration.

- Prefer multimodal assessment of reinstatement effects.

- Carefully control for sequence effects following the reinstatement manipulation and report CS sequences in detail.

- Appreciate that US-recalibrations in multiple-day paradigms likely induce reinstatement effects.

- Acquire data on anxiety-related traits.

- Acquire data on CS-US awareness.

- Consider the role of instructions with respect to CS-US contingencies and report in detail.

Data analysis

- Calculate reinstatement effects using a repeated measures design with time, CS-type (and possibly group), and provide all statistical information to facilitate comparison between different studies.

- Report results for both CS+ and CS - in differential conditioning protocols.

- Include a graphical display based on single-trials following reinstatement for all measurement modalities.

- In case participants are excluded (e.g., based on CS-US unawareness), report if results remain the same when including them. 
rodent work are also able to explain all results in human differential conditioning protocols or whether additional mechanisms (e.g., cognitive processes like expectancy and uncertainty) might play a major role in humans. Finding answers to these questions is of high priority given that reinstatement in humans has recently been established as the major outcome measure for conditioning and extinction memory consolidation manipulations in humans.

Despite of these remaining questions, rodent and human work show quite some parallels (e.g., the role of the context) and more in-depth experimental work in humans and translation to clinical populations is needed, as the prevention of relapse is an important topic from both a scientific and a social point of view. We are at a point, where we know ways to reduce fear, but the current challenge is, how to maintain remission and prevent relapse.

\section{Acknowledgments}

Preparation of this manuscript was supported by the Deutsche Forschungsgemeinschaft (DFG): Collaborative Research Center "Fear, Anxiety, Anxiety Disorders," SFB-TRR 58 subproject B07 (T.B.L.) and by the Center for Excellence on Generalization Research (GRIP-TT; KU Leuven grant PF/10/005 to D.H.).

\section{References}

Boschen MJ, Neumann DL, Waters AM. 2009. Relapse of successfully treated anxiety and fear: theoretical issues and recommendations for clinical practice. Aust N Z J Psychiatry 43: 89-100.

Bouton ME. 1984. Differential control by context in the inflation and reinstatement paradigms. J Exp Psychol Anim Behav Process 10: $56-74$.

Bouton ME. 2004. Context and behavioral processes in extinction. Learn Mem 11: 485-494.

Bouton ME, Bolles RC. 1979. Role of conditioned contextual stimuli in reinstatement of extinguished fear. J Exp Psychol Anim Behav Process 5: $368-378$.

Bouton ME, King DA. 1983. Contextual control of the extinction of conditioned fear: tests for the associative value of the context. J Exp Psychol Anim Behav Process 9: 248-265.

Bouton ME, King DA. 1986. Effect of context on performance to conditioned stimuli with mixed histories of reinforcement and nonreinforcement. J Exp Psychol Anim Behav Process 12: 4-15.

Bouton ME, Peck CA. 1989. Context effects on conditioning, extinction, and reinstatement in an appetitive conditioning preparation. Anim Learn Behav 17: 188-198.

Bouton ME, Rosengard C, Achenbach GG, Peck CA, Brooks DC. 1993. Effects of contextual conditioning and unconditional stimulus presentation on performance in appetitive conditioning. QJ Exp Psychol 46: 63-95.

Cain CK, Godsil BP, Jami S, Barad M. 2005. The L-type calcium channel blocker nifedipine impairs extinction, but not reduced contingency effects, in mice. Learn Mem 12: 277-284.

Craske MG, Kircanski K, Zelikowsky M, Mystkowski J, Chowdhury N, Baker A. 2008. Optimizing inhibitory learning during exposure therapy. Behav Res Ther 46: 5-27.

Craske MG, Wolitzky-Taylor KB, Mineka S, Zinbarg R, Waters AM, Vrshek-Schallhorn S, Epstein A, Naliboff B, Ornitz E. 2012. Elevated responding to safe conditions as a specific risk factor for anxiety versus depressive disorders: evidence from a longitudinal investigation. J Abnorm Psychol 121: 315-324.

Das RK, Kamboj SK, Ramadas M, Yogan K, Gupta V, Redman E, Curran HV, Morgan CJA. 2013. Cannabidiol enhances consolidation of explicit fear extinction in humans. Psychopharmacology 226: 781-792.

Deębiec J, Doyère V, Nader K, LeDoux JE. 2006. Directly reactivated, but not indirectly reactivated, memories undergo reconsolidation in the amygdala. Proc Natl Acad Sci 103: 3428-3433.

Denniston JC, Chang RC, Miller RR. 2003. Massive extinction treatment attenuates the renewal effect. Learn Motiv 34: 68-86.

Dirikx T. 2006. "Reinstatement of conditioned responding in humans and animals. An experimental investigation of differential return of fear." PhD thesis, KU Leuven, Leuven, Netherlands.

Dirikx T, Hermans D, Vansteenwegen D, Baeyens F, Eelen P. 2004. Reinstatement of extinguished conditioned responses and negative stimulus valence as a pathway to return of fear in humans. Learn Mem 11: $549-554$

Dirikx T, Beckers T, Muyls C, Eelen P, Vansteenwegen D, Hermans D, D'Hooge R. 2007a. Differential acquisition, extinction, and reinstatement of conditioned suppression in mice. QJ Exp Psychol (Colchester) 60: 1313-1320.

Dirikx T, Hermans D, Vansteenwegen D, Baeyens F, Eelen P. 2007b. Reinstatement of conditioned responses in human differential fear conditioning. J Behav Ther Exp Psychiatry 38: 237-251.

Dirikx T, Vansteenwegen D, Eelen P, Hermans D. 2009. Non-differential return of fear in humans after a reinstatement procedure. Acta Psychol (Amst) 130: 175-182.

Fonteyne R, Vervliet B, Hermans D, Baeyens F, Vansteenwegen D. 2010. Exposure to the context and removing the unpredictability of the US: two methods to reduce contextual anxiety compared. Biol Psychol 85: $361-369$

Frohardt RJ, Guarraci FA, Bouton ME. 2000. The effects of neurotoxic hippocampal lesions on two effects of context after fear extinction. Behav Neurosci 114: 227-240.

Gazendam FJ, Kindt M. 2012. Worrying affects associative fear learning: a startle fear conditioning study. PLoS One 7: e34882.

Glenn CR, Lieberman L, Hajcak G. 2012. Comparing electric shock and a fearful screaming face as unconditioned stimuli for fear learning. Int J Psychophysiol 86: 214-219.

Golkar A, Öhman A. 2012. Fear extinction in humans: effects of acquisition-extinction delay and masked stimulus presentations. Biol Psychol 91: 292-301.

Golkar A, Bellander M, Olsson A, Ohman A. 2012. Are fear memories erasable? Reconsolidation of learned fear with fear-relevant and fear-irrelevant stimuli. Front Behav Neurosci 6: 80.

Golkar A, Bellander M, Öhman A. 2013a. Temporal properties of fear extinction-does time matter? Behav Neurosci 127: 59-69.

Golkar A, Selbing I, Flygare O, Ohman A, Olsson A. 2013b. Other people as means to a safe end: vicarious extinction blocks the return of learned fear. Psychol Sci.

Grillon C. 2002. Startle reactivity and anxiety disorders: aversive conditioning, context, and neurobiology. Biol Psychiatry 52: 958-975.

Grillon C, Baas JMP, Cornwell B, Johnson L. 2006. Context conditioning and behavioral avoidance in a virtual reality environment: effect of predictability. Biol Psychiatry 60: 752-759.

Grupe DW, Nitschke JB. 2013. Uncertainty and anticipation in anxiety: an integrated neurobiological and psychological perspective. Nat Rev Neurosci 14: 488-501.

Haaker J, Gaburro S, Sah A, Gartmann N, Lonsdorf TB, Meier K, Singewald N, Pape HC, Morellini F, Kalisch R. 2013a. Single dose of L-dopa makes extinction memories context-independent and prevents the return of fear. Proc Natl Acad Sci. doi: 10.1073/ pnas. 1303061110.

Haaker J, Lonsdorf TB, Thanellou A, Kalisch R. 2013b. Multimodal assessment of long-term memory recall and reinstatement in a combined cue and context fear conditioning and extinction paradigm in humans. PLoS One 8: e76179.

Hall G. 1996. Learning about associatively activated stimulus representations: implications for acquired equivalence and perceptual learning. Anim Learn Behav 24: 233-255.

Halladay LR, Zelikowsky M, Blair HT, Fanselow MS. 2012. Reinstatement of extinguished fear by an unextinguished conditional stimulus. Front Behav Neurosci 6: 18.

Harris JA, Jones ML, Bailey GK, Westbrook RF. 2000. Contextual control over conditioned responding in an extinction paradigm. J Exp Psychol Anim Behav Process 26: 174-185.

Hermans D, Dirikx T, Vansteenwegen D, Baeyens F, Van den Bergh O, Eelen P. 2005. Reinstatement of fear responses in human aversive conditioning. Behav Res Ther 43: 533-551.

Holland PC. 1981. Acquisition of representation-mediated conditioned food aversions. Learn Motiv 12: 1-18.

Huff NC, Hernandez JA, Blanding NQ, LaBar KS. 2009. Delayed extinction attenuates conditioned fear renewal and spontaneous recovery in humans. Behav Neurosci 123: 834-843.

Kalisch R, Korenfeld E, Stephan KE, Weiskopf N, Seymour B, Dolan RJ. 2006. Context-dependent human extinction memory is mediated by a ventromedial prefrontal and hippocampal network. J Neurosci 26: 9503-9511.

Kattoor J, Gizewski ER, Kotsis V, Benson S, Gramsch C, Theysohn N, Maderwald S, Forsting M, Schedlowski M, Elsenbruch S. 2013a. Fear conditioning in an abdominal pain model: neural responses during associative learning and extinction in healthy subjects. PLoS One 8: e51149.

Kattoor J, Thürling M, Gizewski ER, Forsting M, Timmann D, Elsenbruch S. $2013 \mathrm{~b}$. Cerebellar contributions to different phases of visceral aversive extinction learning. Cerebellum. 
Kellett J, Kokkinidis L. 2004. Extinction deficit and fear reinstatement after electrical stimulation of the amygdala: implications for kindlingassociated fear and anxiety. Neuroscience 127: 277-287.

Kim JH, Richardson R. 2007. A developmental dissociation in reinstatement of an extinguished fear response in rats. Neurobiol Learn Mem 88: 48-57.

Kindt M, Soeter M. 2013. Reconsolidation in a human fear conditioning study: a test of extinction as updating mechanism. Biol Psychol 92: $43-50$.

Kindt M, Soeter M, Vervliet B. 2009. Beyond extinction: erasing human fear responses and preventing the return of fear. Nat Neurosci 12: $256-258$.

Kull S, Müller BH, Blechert J, Wilhelm FH, Michael T. 2012. Reinstatement of fear in humans: autonomic and experiential responses in a differential conditioning paradigm. Acta Psychol (Amst) 140: $43-49$.

LaBar KS, Phelps EA. 2005. Reinstatement of conditioned fear in humans is context dependent and impaired in amnesia. Behav Neurosci 119: 677-686.

Laurent V, Westbrook RF. 2010. Role of the basolateral amygdala in the reinstatement and extinction of fear responses to a previously extinguished conditioned stimulus. Learn Mem 17: 86-96.

Leweke FM, Piomelli D, Pahlisch F, Muhl D, Gerth CW, Hoyer C, Klosterkötter J, Hellmich M, Koethe D. 2012. Cannabidiol enhances anandamide signaling and alleviates psychotic symptoms of schizophrenia. Transl Psychiatry 2: e94.

Lissek S, Powers A, McClure E, Phelps E, Woldehawariat G, Grillon C, Pine D. 2005. Classical fear conditioning in the anxiety disorders: A meta-analysis. Behav Res Ther 43: 1391-1424.

Lissek S, Rabin S, Heller RE, Lukenbaugh D, Geraci M, Pine DS, Grillon C. 2010. Overgeneralization of conditioned fear as a pathogenic marker of panic disorder. Am J Psychiatry 167: 47-55.

Lonsdorf TB, Haaker J, Fadai T, Kalisch R. 2014a. No evidence for enhanced extinction memory consolidation through noradrenergic reuptake inhibition-delayed memory test and reinstatement in human fMRI. Psychopharmacology. 231: 1949-1962.

Lonsdorf TB, Haaker J, Kalisch R. 2014b. Long-term expression of human contextual fear and extinction memories involves amygdala, hippocampus and ventromedial prefrontal cortex: A reinstatement study in two independent samples. Soc Cogn Affect Neurosci. doi: $10.1093 /$ scan/nsu018.

Maier S, Szalkowski A, Kamphausen S, Perlov E, Feige B, Blechert J, Philipsen A, van Elst LT, Kalisch R, Tüscher O. 2012. Clarifying the role of the rostral dmPFC/dACC in fear/anxiety: learning, appraisal or expression? PLoS One 7: e50120.

Maren S. 2011. Seeking a spotless mind: extinction, deconsolidation, and erasure of fear memory. Neuron 70: 830-845.

Maren S, Phan KL, Liberzon I. 2013. The contextual brain: implications for fear conditioning, extinction and psychopathology. Nat Rev Neurosci 14: $417-428$.

Marschner A, Kalisch R, Vervliet B, Vansteenwegen D, Büchel C. 2008. Dissociable roles for the hippocampus and the amygdala in human cued versus context fear conditioning. J Neurosci 28: 9030-9036.

Mechias M-L, Etkin A, Kalisch R. 2010. A meta-analysis of instructed fear studies: implications for conscious appraisal of threat. NeuroImage 49: $1760-1768$.

Milad MR, Orr SP, Pitman RK, Rauch SL. 2005. Context modulation of memory for fear extinction in humans. Psychophysiology 42: 456-464.

Milad MR, Wright CI, Orr SP, Pitman RK, Quirk GJ, Rauch SL. 2007. Recall of fear extinction in humans activates the ventromedial prefrontal cortex and hippocampus in concert. Biol Psychiatry 62: 446-454.

Morris RW, Westbrook RF, Killcross AS. 2005. Reinstatement of extinguished fear by $\beta$-adrenergic arousal elicited by a conditioned context. Behav Neurosci 119: 1662-1671.

Myers KM, Davis M. 2007. Mechanisms of fear extinction. Mol Psychiatry 12: $120-150$.

Myers KM, Ressler KJ, Davis M. 2006. Different mechanisms of fear extinction dependent on length of time since fear acquisition. Learn Mem 13: 216-223.

Nader K, Schafe GE, Le Doux JE. 2000. Fear memories require protein synthesis in the amygdala for reconsolidation after retrieval. Nature 406: $722-726$, [see comments].

Norrholm SD, Jovanovic T, Vervliet B, Myers KM, Davis M, Rothbaum BO, Duncan EJ. 2006. Conditioned fear extinction and reinstatement in a human fear-potentiated startle paradigm. Learn Mem 13: $681-685$.

Norrholm SD, Vervliet B, Jovanovic T, Boshoven W, Myers KM, Davis M, Rothbaum B, Duncan EJ. 2008. Timing of extinction relative to acquisition: a parametric analysis of fear extinction in humans. Behav Neurosci 122: 1016-1030.

Pavlov IP. 1927. Conditioned reflexes. Oxford University Press, London, UK.

Pearce JM, Bouton ME. 2001. Theories of associative learning in animals. Annu Rev Psychol 52: 111-139.

Pearce JM, Hall G. 1980. A model for Pavlovian learning: variations in the effectiveness of conditioned but not of unconditioned stimuli. Psychol $\operatorname{Rev}$ 87: 532-552.

Pineño O, Miller RR. 2004. Signaling a change in cue-outcome relations in human associative learning. Learn Behav 32: 360-375.

Quirk GJ, Mueller D. 2008. Neural mechanisms of extinction learning and retrieval. Neuropsychopharmacology 33: 56-72.

Rescorla RA. 1979. Conditioned inhibition and extinction. In Mechanisms of learning and motivation: a memorial volume to Jerzy Konorski (ed. Dickinson A, Boakes RA), pp. 83-110. Erlbaum, Hillsdale, NJ.

Rescorla RA, Cunningham CL. 1977. The erasure of reinstated fear. Anim Learn Behav 5: 386-394.

Rescorla RA, Heth CD. 1975. Reinstatement of fear to an extinguished conditioned stimulus. J Exp Psychol Anim Behav Process 1: $88-96$.

Rescorla R, Wagner A. 1972. A theory of Pavlovian conditioning: variations in the effectiveness of reinforcement and nonreinforcement. In Classical conditioning II: current research and theory (ed. Black A, Prokasy W), pp. 64-99. Appleton-Century-Crofts, New York.

Richardson R, Riccio DC, Devine L. 1984. ACTH-induced recovery of extinguished avoidance responding. Physiol Psychol 12: 184-192.

Richardson R, Duffield TQ, Bailey GK, Westbrook RF. 1999. Reinstatement of fear to an extinguished conditioned context. Anim Learn Behav 27: 399-415.

Schiller D, Cain CK, Curley NG, Schwartz JS, Stern SA, Ledoux JE, Phelps EA. 2008. Evidence for recovery of fear following immediate extinction in rats and humans. Learn Mem 15: 394-402.

Schiller D, Monfils M-H, Raio CM, Johnson DC, LeDoux JE, Phelps EA. 2010. Preventing the return of fear in humans using reconsolidation update mechanisms. Nature 463: 49-53.

Schmajuk NA, Larrauri JA, Labar KS. 2007. Reinstatement of conditioned fear and the hippocampus: an attentional-associative model. Behav Brain Res 177: 242-253.

Sevenster D, Beckers T, Kindt M. 2012a. Instructed extinction differentially affects the emotional and cognitive expression of associative fear memory. Psychophysiology 49: 1426-1435.

Sevenster D, Beckers T, Kindt M. 2012b. Retrieval per se is not sufficient to trigger reconsolidation of human fear memory. Neurobiol Learn Mem 97: $338-345$.

Sevenster D, Beckers T, Kindt M. 2013. Prediction error governs pharmacologically induced amnesia for learned fear. Science 339: 830-833.

Soeter M, Kindt M. 2010. Dissociating response systems: erasing fear from memory. Neurobiol Learn Mem 94: 30-41.

Soeter M, Kindt M. 2011. Disrupting reconsolidation: pharmacological and behavioral manipulations. Learn Mem 18: 357-366.

Sokol N, Lovibond PF. 2012. Cross-US reinstatement of human conditioned fear: return of old fears or emergence of new ones? Behav Res Ther 50: $313-322$.

Vervliet B, Baeyens F, Van den Bergh O, Hermans D. 2013a. Extinction, generalization, and return of fear: a critical review of renewal research in humans. Biol Psychol 92: 51-58.

Vervliet B, Craske MG, Hermans D. 2013b. Fear extinction and relapse: state of the art. Annu Rev Clin Psychol 9: 215-248.

Wade SL, Monroe SM, Michelson LK. 1993. Chronic life stress and treatment outcome in agoraphobia with panic attacks. Am J Psychiatry 150: $1491-1495$

Weike AI, Schupp HT, Hamm AO. 2007. Fear acquisition requires awareness in trace but not delay conditioning. Psychophysiology 44: $170-180$.

Westbrook RF, Iordanova M, McNally G, Richardson R, Harris JA. 2002. Reinstatement of fear to an extinguished conditioned stimulus: two roles for context. J Exp Psychol Anim Behav Process 28: $97-110$.

Wilson A, Brooks DC, Bouton ME. 1995. The role of the rat hippocampal system in several effects of context in extinction. Behav Neurosci 109: 828-836.

Woods AM, Bouton ME. 2008. Immediate extinction causes a less durable loss of performance than delayed extinction following either fear or appetitive conditioning. Learn Mem 15: 909-920.

Received June 7, 2014; accepted in revised form June 17, 2014. 


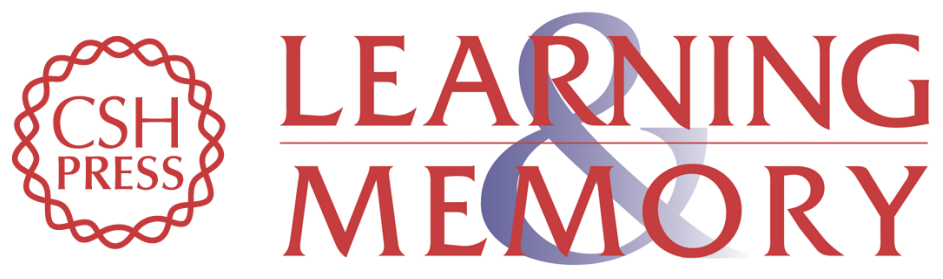

\section{A review on human reinstatement studies: an overview and methodological challenges}

Jan Haaker, Armita Golkar, Dirk Hermans, et al.

Learn. Mem. 2014, 21:

Access the most recent version at doi:10.1101/lm.036053.114

References This article cites 87 articles, 14 of which can be accessed free at: http://learnmem.cshlp.org/content/21/9/424.full.html\#ref-list-1

Creative This article is distributed exclusively by Cold Spring Harbor Laboratory Press for the Commons License first 12 months after the full-issue publication date (see

http://learnmem.cshlp.org/site/misc/terms.xhtml). After 12 months, it is available under a Creative Commons License (Attribution-NonCommercial 4.0 International), as described at http://creativecommons.org/licenses/by-nc/4.0/.

Email Alerting Receive free email alerts when new articles cite this article - sign up in the box at the Service top right corner of the article or click here. 